Portland State University

PDXScholar

5-13-1974

\title{
The impact of college speech classes on listening skills of students.
}

Candice Piazza

Portland State University

Follow this and additional works at: https://pdxscholar.library.pdx.edu/open_access_etds

Part of the Cognition and Perception Commons, and the Communication Commons Let us know how access to this document benefits you.

\section{Recommended Citation}

Piazza, Candice, "The impact of college speech classes on listening skills of students." (1974).

Dissertations and Theses. Paper 2014.

https://doi.org/10.15760/etd.2013

This Thesis is brought to you for free and open access. It has been accepted for inclusion in Dissertations and Theses by an authorized administrator of PDXScholar. Please contact us if we can make this document more accessible: pdxscholar@pdx.edu. 
AN ABSTRACT OF THE THESIS OF Candice Piazza for the Master of Science in Speech: Emphasis Speech Pathology/Audiology

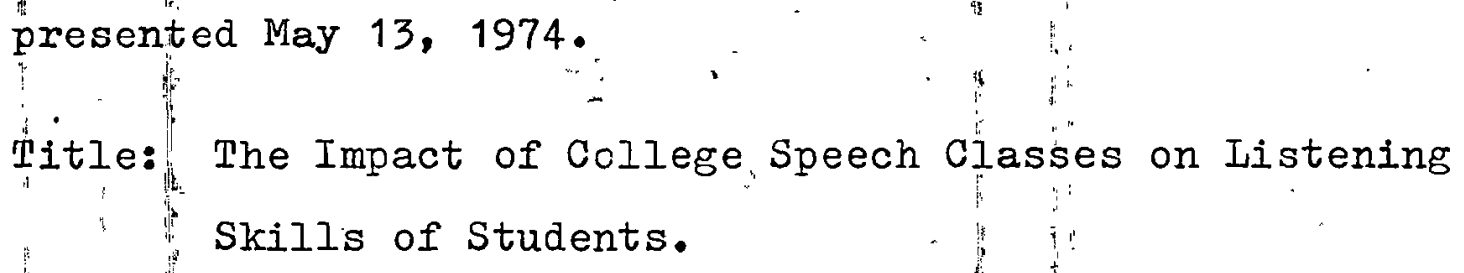

Title: The Impact of College Speech Classes on Iistening Skills of Students.

APPROVED BY MEMBERS OF THE THESIS COMMITTEE:

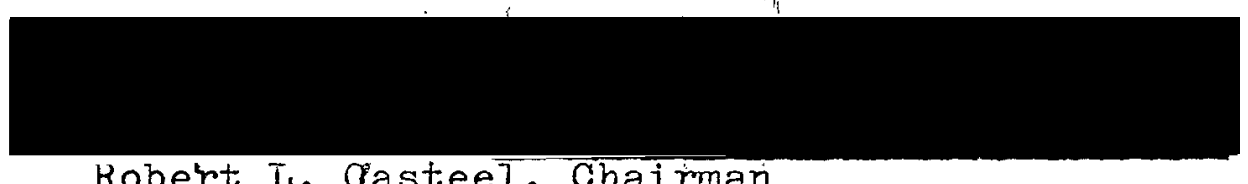

Robert I. OasteeI, Chairman

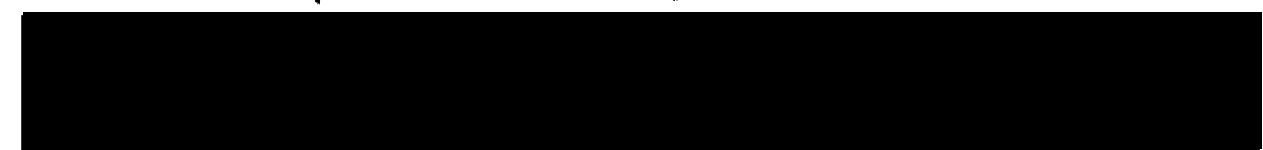

$$
\text { rodert H. English }
$$

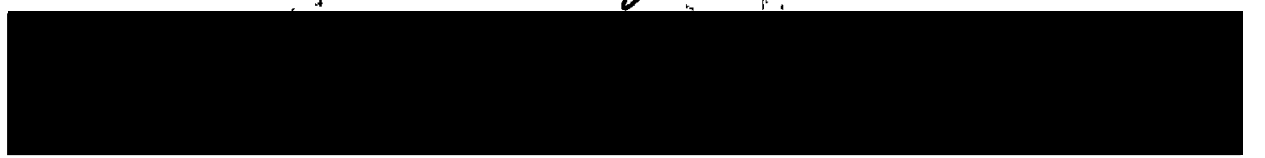

llary Li. liofaon

The purpose of this study was to determine the impact of college speech classes upon developing improved listening skilis. More specifically, it sought to determine the extent to which the students who:took Speech 100 or 111 have acquired listening skills.

There has been considerable theorizing concerning listening and auding with only a scattering of experimentation. According to existing data, listening would appear to be a complex human behavior that is "nly" partially 
understood. There are, however, definite listener functions, listening conditions and variables that affect listening. Aspects of attention are alsoimportant when considering the occurrence or unoccurrence of listening. Initially, the Listening Attitude Test (IAT) was developed in order to measure conceptual changes in listening skills. The LAT was statisticaily analyzed to determine its validity. This test was then presented to three different student populations: 1) students who had just completed Speech 100 or $111 ; 2)$ students who were at least one academic year removed from Speech 100 or 111; and 3) students who have never had Speech 100 or 111. All of the ptudents from these three populations were selected from Speech 100, Speech, 111 or English Composition classes at Portland State University. The performance of the three populations were statistically compared using the $t$ test to determine the significance of differences between means. The following is a summary of the findings. The LAT was correlated with the Brown-Carlsen Iistening Comprehension Test Parts $A, E$ and $A$ and E combined The results indicated that the IAT was testing what it purported to test, to the data from three different student populations that took the LAT. The results indicated that there was no statistically significant difference, between students who have not had Speech 100 or 111 and those who have just 
completed Speech 100 or 111. There was a significant difference between students who have just completed speech 100 or 111 and those who have completed speech 100 or 111 but are at least one academic year removed from it. In addition, a significant difference was revealed between students who have not had Speech 100 or 111 and those who completed speech 100 or 111 but are at least one academic year removed from it.

It is clear that the findings support those contending that exposure to speech improve listening skills. The claim made by Nichols and Lewis (1954) that instruction in Histening skills would improve listening was not supported by the "just completed group" data and no single overriding hypothesis seems to account for this discrepancy. Nichol's and Lewis (1954), however, were dealing with college. speech courses which were heavily loaded "with training techniques for improving listening ability, which was not the case in Speech 100 or 111 courses at Portland State University. 


\title{
THE IMPACT OF COLLEGE SPEECH CIASSES
}

ON IISTENING SKILUS OF STUDENTS

\author{
by \\ CANDICE PIAZZA
}

A thesis submitted in partial fulfillment of the requirements for the degree of

MASTER OF SCIENCE in

SPEECH: EMPHASIS SPEECH PATHOLOGY/AUDIOLOGY

Portland State University

1974 
ACKNOWLEDGMENTS

The writer wishes to acknowledge the following for their special contributions to this study Dr. Robert.I. Casteel, who served as chairman of my thesis committee and whose perceptive critiques and valuable guidance and support were given freely and frequently throughout this study. Without this, the study would never have become reality.

Dr. Robert H. English, a member of my committee whose invaluable critiques greatly improved this study. Mary E. Gordon, another member of my committee whose guidance, critiques, support and valued friendship was deeply appreciated.

The staff members of the Speech Department and English Department of Portland State University for their time and cooperation in volunteering their classes for use in this investigation.

A special thanks to Dr. Hegrenes; whose wonderful "white horse" saved this statistically perplexed damsel. I am deeply indebted to him for his generous assistance and guidance in the statistical treatment of data. Finally, for his great understanding; patience and support during this thesis and always, I thank my husband, Steve. His faith in me and in my abilities made it possible to survive during this period of time and to succeed at a task once thought impossible. 
ACKNOWLEDGMENTS • • • • • • • • • • • CHAPTER

I INTRODUCTION AND STATEMENT OF PROBLEN . . • 1 Genesis of the Problem. $: \because \cdots 1$ Importance of Iistening"..".". . . 6 Statement of the Problem. $\because \cdots \cdots, \ldots$ Definitions . . . . . . . . 9

II SURVEY OF THE IITERATURE. . . . : 12

General Overview of Iistening Theories and Studies ..........

Iistener Functions

Conditions for listening

Variables Affecting Iistening

Discussion of Attention

Levels of Attention

Selective Attention:

Span of Attention

Characteristics and Measurement of Iistening . . . . ... . . .

Ten Characteristics of Good and Poor Iisteners

Measurement of Iistening Behavior

Tests of Iistening 
$\vdots$
CHAPTER

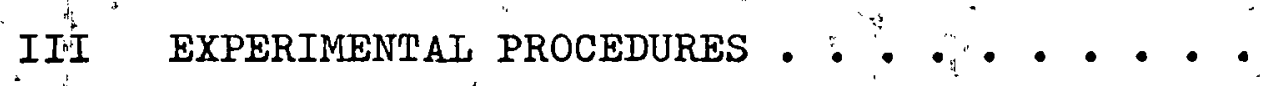

The Test Instruments.

Iistening Attitude Test

Brown-Carlsen Lilstening

Comprehension Test

The Procedures and Methods Úsed: • •

Subjects

Administration of Test Instruments. • •

Data Analysis : . . . . . . . . 46

IV RESULTS AND DISCUSSION. • • • • • • • • • 48

Results . . . . . . . . . . . . 48

Discussioñ. ........... 50

V SUMMARY AND IMPLICATIONS FOR FURTHER

RESEARCH. •. . . ‘. • •. . . . 55 .

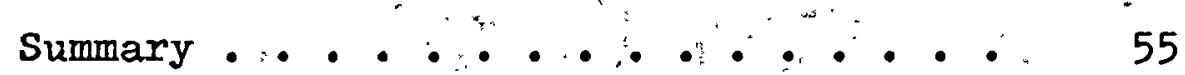

Implications for Further Research... $\cdot 57$

BIBIIO'GRAPHY APPENDIX

A Listening Attitude Test . . . . . . . 66

B Part A and E Form Am of Brown-Carlsen

* Iistening Comprehension Test. • • • • •

C Inter-Item Correlation Matrix of the Total

Population. ....................

D Validity, Difficulty and Split Half Reliability Coefficients for the BrownCarlsen Listening Comprehension Tests,

Form Am . . . . . . . . . ! . . . . .

82

E Instructions Read to Subjects Before BrownC Carlsen Listening Comprehension Test. . . 
vi

APPENDIX

PAGE

F Instructions Read to Subjects Before Listening Attitude Test........"......

G Raw Data on the IAT and the Brown-Carlsen Test Parts $A, E$ and $A$ and $E$ Combined. ... 


\section{CHAPTER I}

\section{INTRODUCTION AND STATEMENT OF/ PROBLEM}

" No subject of curiosity has plagued parents, teachers, business executives and many others, as the phenomenon referred to as "listening." There are many reasons for this concerm, all of which probably are justified. An attempt. to clarify what is meant by listening will be made by discussing the various definitions and tho studies that are concerned with this subject.

It has been postulated by Nichols $(1957)$ that those people who are able to listen for whole ideas rather than bits and pieces of what is said have very" often studied public speaking." He feels that public ispeaking classes.may indirectly teach a student the importance of good listening habits This study attempts to. test this hypothesis.

\section{GENESIS OF THE PROBIEM}

There is general agreement that the term "Iistening" implies more than the mere perception of sound. Beyond that, however, it is difficult to generalize. Brown (1961), Caffrey (1961), and Furness (1961), have written of the confusion that has resulted from the variety of meanings attributed to the term "Iistening." Petrie (1961) attributes 
this confusion to two factors: 1) "the fact that the event designated by the term "listening" is a dynamic, psychophysical "process;" and 2), "the -lack of adequate knowledge about "this listening process."

Investigators have differed in the emphasis they have placed on the various elements, structure, and limits of this process. No single, definition is right or wrong by any means. Writers may be talking about different processes or they may be viewing the same process from different angles. Whatever the case might be, confusion relative to a particular meaning and use of the term "listening" has resulted. Other difficulties in defining listening have resulted from allack of adequate knowledge about the elements which compose the listening process. A general point-of-view represented by Petrie suggests that:

$\therefore$ : the actual amount of objective information obtained as a result of careful research employing rigorous scientific procedures is so meager that any generalizations with reference to the process would be precarious if not in most instances, actually invalid (Petrie, 1961).

Âs a result, in defining listening, it is necessary to rely upon speculation and educated guesses which frequently are open to serious question and doubt.

t.

Among the various definitions of listening which have been suggested are the following:

- . an analysis of the impressions resulting from concentration where an effort of "will, is required

(Tucker, 1961). 
. . the attachment of meaning to aural symbols (Nichois, 1948).

- . understanding spoken language (Rankin, 1926).

- . comorising both receptive and reflective listening . . . reception . . In terms of 1 . getting lecture details, 2. following oral directions, and 3. keeping a sequence of details in mind. Reflective, or critical, listening ... in terms of 1. getting central ideas, 2. drawing inferences, 3. using contextual clues to determine word meanings, and 4. identifying transitional elements (Brown, 1950).

- a selective process by which sounds communicated by some source are received, critically interpreted, and acted upon by a purposeful listener (Jones, 1961).

- . the process of reacting to, interpreting, and relating the spoken language in terms of past experiences and future courses of action (Barbe and Niyers, 1961).

- . the conscious purposeful registration of sounds upon the mind (which) leads to further mental activity $\cdot \dot{6}$ all true listening is creative (Hook, 1961).

- . the capacity of an individual to understand spoken language in the presence of a speaker (Still, 1961).

These definitions reveal differing approaches to the definition of the listening process. Some of them give little insight into what the listening process entails. Jones (1961) has been critical of exacting attempts to define listening particularly those advanced by Nichols (1948) and Brown (1950), he writes that whenever:

- - an attempt to define listening is made, generally one may get as far as 'listening is . . .' and then because listening is such an amorphous concept, the writers change direction and try to define listening simply by enumerating what it involves. This is the same as defining cooking by stating that 
it is baking, boiling, frying, and broiling, and ignoring completely the fact that all cooking is a process whereby heat of varying degrees, etc., is applied to certain organic substances to produce certain reactions, or something of the sort.

Jones (1961) further suggests that the listening process involves both "Iistening to" sounds and "listening for" certain sounds and meanings. Jones (1961) and Barbe and Myers (1961) also call attention to the importance of memory factors, predispositions, and past experience in listening comprehension. These writers all agree that listening, unlike hearing, requires conscious effort. As Hook (1961) states:

One hears the sound of passing cars and it leaves no mental impression; but he listens to find the source of a squeak in his own car, and then he tries to do something about it. Iistening, that is caused by mental activity ... .

Some writers insist that listening includes the "observation of communication as well as its audition" (Baird and Knower, 1959). It can hardly be argued that there is a visual factor involved . . for example, when a speaker is present. However, when one attends to a radio or tape recorder, listening continues even though there is no visual factor involved. Consequently, to include visual factors as a necessary component of listening, seems to restrict the meaning of the term (Petrie, 1961).

It should be noted that Rankin (1926), Brown (1950), Nichols (1948), Barbe and Myers (1961), Still (1961), and Baird and Knower (1961) have all limited their definitions 
to the inclusion of attachment of meaning to "verbal symbols."

Tucker (1961), Jones (1961) and Hook (1961) have included activities such as listening for meaning in the "squeak" of a car. The above definitions of listening demonstrates the confusion a broad term such as "Iistening" may present.

Brown (1961) felt that listening is an ambiguous term and that a term is needed which is clearly distinguishable from hearing and listening. He has suggested the term "auding." By definition, auding is the gross process of "listening to, recognizing, and interpreting spoken symbols." Furness (1961), in a review of listening, also concluded that auding is perhaps a more accurate term:

The evidence seems to indicate that the term "listening" as it is commonly employed today is inadequate. The evidence seems to indicate too, that comprehending aurally or "auding" is the more adequate term; and that "auding" consists of at least six processes: (a) hearing, (b) listening, (c) recognizing spoken language, (d) interpreting oral symbols, (e) supplementing meaning and knowledge of the symbols, and ( $f$ ) being aware of facts or assumptions not uttered.

As used in this definition, the term "listening" apparently means "attending to spoken language with the intent to acquire meaning" (Petrie, 1961). On the whole, Furnes's (1961) definition seems to be a reasonable description of the process of comprehending oral language. It is considered specific enough to designate a precise process and it also is broad enough to include most of the factors that other investigators may consider important. 
Hardy (1956) includes six steps in his definition of the term "auding" which could be used in forming a scale to provide a basis for establishing a program of rehabilitation for children with auditory problems.

The first three steps are concerned with hearing-sensitivity; the second three are concerned with auding--listening. The hearing steps are: I, sensitivity; II, discrimination and III, perception (or recognition). The auding steps are: IV, processing; $V$, patterm making, and VI, retention. A final step has been added to express the awareness of concepts, VII, conceptualization.

Petrie (1961) uses the term "listening" or "listening comprehension" synonymously with "auding." Their meaning is the

composite process by which oral lánguage communicated by some source is received, critically and purposefully attended to, recognized, and interpreted (or comprehended) in terms of past experiences and future expectancies.

The total process includes the six speciflc elements included in Furness' (1961) definition. This total process is considered as the definition of listening that will be referred to throughout this study. Ten characteristics of "good" and "poor" listeners proposed by Nichols and Lewis (1954) are important when considering a meaningful definition of "listening" and will be discussed later.

\section{IMPORTANCE OF IISTENING}

It has long been recognized that hearing and interpreting spoken language with understanding is important to both learning and communicating in a meaningful way. 
Although Taylor (1964) has noted that 90 percent of the listening research has been accomplished since 1952, research established in 1926 (Rankin) that 70 percent of the average adult's working day was spent in verbal communication of which 45 percent of the communication time was spent in listening activities. In this early study by Rankin, individuals kept a record for 60 days of their time, which indicated that listening occupies an average of about 29.7 percent of the average waking day. Listening is used more than talking, three times as much as reading, and four times as much as writing. In 1949 an exploration of listening in the elementary classroom led to the discovery that 57.5 percent of the class time was spent in listening situations (Brown, 1950). In the late 1950's and early $1960^{\prime} \mathrm{s}$, it was estimated that close to 90 percent of the class time in high schools and colleges is spent in listening to discussions and lectures (Brown, 1950).

Since the advent of television, the proportion of time spent in listening has been increasing for life in general. Paul Witty (1959) reports that children now average upwards of twenty hours per week with television. Figures were not found on time spent in listening to the radio, however, this would make an interesting comparison.

It seems amazing that the average person will retain only 50 percent of what he hears upon immediate recall, no matter how hard he concentrates, and that two months later 
he can be expected to recall only twenty-five percent of what he heard (Taylor, 1964).

It seems ironic that we are not profiting more from listening, especially when considering the amount of time invested in this activity. To use the time spent listening more efficiently, it is necessary to develop one's listening skills maximally.

\section{STATEMENT OF THE PROBLEM}

The purpose of the present study has sought to determine the impact of college speech classes upon developing improved listening skills. More specifically, it seeks to determine the extent to which the students have acquired listening skills.

Three basic questions are raised by the present study:

1. Will there be a significant difference in the conceptions of listening skills between students who have not had Speech 100 or Speech 111 and those who have just completed Speech 100 or 111 Fall term 1970 ?

2. Will there be a difference in the conceptions of listening skills between students who have just completed Speech 100 or Speech 111 Fall term 1970 and those who have completed Speech 100 or 111 but are at least an academic year removed from it?

3. Will there be a difference in the conceptions of listening skills between students who have not had Speech 100 
or Speech 111 and those who completed Speech 100 or 111 but are at least an academic year removed from it?

\author{
DEFINITIONS
}

\title{
Listening
}

For the purpose of the present study, listening will be operationally defined after Petrie (1961). He states that listening is:

The . - composite process by which oral language communicated by some source is received, critically and purposefully attended to, recognized, and interpreted (or comprehended). in terms of past experiences and future expectancies.

In order for this listening process to take place, sëveral basic elements must be present. Initially, the message must be heard and attended to purposefully. Then the spoken language must be recognized and the oral symbols understood. Finally meaning and knowledge of the symbols are complemented by past experiences, future needs and by "the awareness of the assumptions that were not verbalized (Furness, 1961).

Conceptions of Listening Skills

This term will refer to the attitudes, ideas, and beliefs a person has towards listening and listening skills. Maintenance of Listening

The listener cannot be a speaker at the same time and must have some kind of referential information with the 
speaker. The setting also is important in maintenance.

Onset of Listening

Before listening can begin, the speaker must be identified by the potential listener and the listener. must identify himself as such.

Referential Language

Language in which something is referred to, or which constitutes a reference; and such language-may serve as , stimuli for speaker and listener activity.

Selective Attention

This term refers to the attending to a restricted aspect of the stimulus.

Span of Attention

This term refers to two different phenomena:

(a) the number of distinct objects that can be perceived in a single momentary presentation; and (b) the length of time a person can attend to one thing (Powers; 1969).

\section{Speaker Concurrent Actions}

This term refers to actions of the speaker that affect the onset, maintenance, and termination of listening.

\section{Statement-directing}

This refers to a referential listener function in which the listener performs certain immediate acts as a 
function of his interaction. with the speaker's statement. Such: as the Iistener noding his head in reaction to the speaker's statement.

Statement-modification

A term referring to a 'referential istener function in which the listener modifies the speaker statement before demonstrating any subsequent behavior.

Statement-recording ,

A referential listener function in which the listener knows the speaker's referent. In other words, the listener hais an understanding of the subject being referred to by the speaker.

Stroke.

This is not, truly a referential function but occurs frequently. The listener is not attending to the speaker's statements, but is listening for the speaker to cease talking.

Termination of Listening

This term refers to dismuptive behavior on the part of the speaker or listener that may temporarily terminate listening. The setting also may affect listening negatively.

It is believed that, the above definitions will aid the reader in his understanding of this study. 
CHAPTER II

\section{SURVEY OF THE IITERATURE}

A review of the literature revealed considerable theorizing concerning listening and auding with some experimentation. As indicated in the introduction above, listening is a complex behavior and only partially understood. In order to provide for an organized and controlled survey or review of the literature, the following discussion will be divided into three convenient, major headings. These will include: 1) a general overview of listening theories and studies; 2) a discussion of attention; and 3), characteristics and measurement of listening.

\section{GENERAI OVERVIEW OF IISTENING} THEORIES AND STUDIES

\section{Listener Functiong}

The listener may attend to speaker statements in several different ways, and these different ways of listening are used to characterize the major listener functions. Such a. characterization suggests that listening is not a unitary function, and the way in which the listener interacts with the speaker's statements reflects the particular function he is filling at that time (Bakan, 1956; Rice and Ratner, 1967). 
In referential language, listening may be described as part of a chain of interactions in which each listener's respönse serves as a stimulus for furthèr responses. Some of these responses may serve primarily as stimuli for speaker activity and others may serve primarily as stimuli for listener activity (Rice and Ratnèr, 1967).

Three referential listener-statement functions were proposed by Rice and Ratner.(1967): 1) statement-recording; 2) statement-directing; and 3) statement-modification.

1. The characteristic of the listener referred to as statement-recording is when the listener understands the speaker's referent. An example cited was hearing someone recite a telephone number or hearing someone give directions. This characteristic is basic to referential iistening. The statements of the speaker determine to what extent this characteristic is present in the listener-statement functions.

2. As a function of interacting with the speaker's statement, the Iistener may demonstrate certain immediate acts. This characteristic was referred, to as statementdirecting listening and was demonstrated by the listener directing his behavior either toward interaction with the actual referent or toward interaction with himself. This (his) behavior is strongly influenced by the speakerlistener relationship and the setting in which (the) interaction takes place. It is necessary for the listener to 
first record the statement before he can perform a statementdirecting function. It was interesting to note that the statement-recording and the statement-directing functions do not necessarily need to be human. As an example, referential listening is taking place by a dog when taught to perform various tasks, upon reception of a vocal signal. The extent that these tasks are carried out is dependent upon the speaker, intonation, and setting. In other words, the ability to talk is not necessary to fulfill the characteristics of the statement-recording and statementdirecting functions.

3. The third characteristic of the listener was referred to as statement-modification and occurs when the Iistener modifies the speaker's statement before demonstrating any subsequent behavior. It usually takes place when listening to a lecture or to a conversation. The listener first records the statement then directs his behavior by relating the statement to his personal ideas, feelings or memories. As a result of this action, the referential statement will become modified in that it will differ to some extent from the original reference made by the speaker. Statement-modification was considered to be a specialized form of statement-directing in that the listener directs his behavior by interacting with himself without the speaker requiring him to do so and because of this interaction, the referential statement has been changed. After 
statement-modification, the listener may change his role to that of the speaker, or may begin listening again (since he had to stop listening to modify the statement and must begin to record again before he can again modify the statement), or he may stop listening completely.

According to Rice and Ratner (1967), another listener reaction, not considered to be a referential listener-statement function, frequently occurs and should be mentioned. This was called ritualistic or stroke listening and has been described by Berne (1964). Rice and Ratner (1967) stated that this reaction occurs in normal greetings such as, "Hello, how are you?", or when the listener is faking attention to the speaker's statement for the reason of "pleasing" him. Stroke listening can occur independently or along with statement-modification listening. When interspersed with statement-modification listening, it usually follows a statement-directing reaction. While the listener is modifying a particular statement, he cannot attend to the speaker statement occurring at that time; however, he continues to give the impression that he is attending by nodding his head and/or looking intently at the speaker. Stroke listening and referential listening cannot occur together.

The four descriptions above characterize the various functions in which a listener may participate as he interacts with himself, a speaker, a speaker's statement, and a referent in a particular setting (Rice and Ratner, 1967). 
As Rice and Ratner's (1967) three characteristics and stroke listening are viewed in relation to one another, other listener behaviors were deemed to be important. First, in any given speaker-listener interaction the listener is serving all of these functions at different times. In conversational listening, these functions are usually in an orderly sequence. This means that the listener respectively performs statement-recording, -directing, -modification, and then finally strokes, until he himself becomes a speaker.

Statement-modification becomes a powerful stimulus for changing from listening to speaking activity, and if a speaking response does not immediately follow statementmodification, the listener will usually stroke until he is able to become a speaker. In situations such as a lecture, however, the listener may be performing these functions in a more irregular manner. Any measurement, therefore, of these functions needs to be sensitive to variables other than the general setting of the interaction. That is, it cannot be assumed that these functions occur in an orderly manner (Rice and Ratner, 1967).

In relation to one another, these major liștener characteristics suggested a developmental sequence in which children may first learn to stroke (a non-referential function), and then to record, direct, and modify speaker statements. These characteristics also may reflect speaking as well as listening functions. 
Another way of viewing listener functions was suggested" by Fessenden (1955) who hypothe sized that listening is composed of seven different levels, some of which merge with those discussed above. They were: 1) isolate sounds, ideas, arguments, facts, and so on; 2) identify or give meaning; 3) integrate what we hear with our past experiences; 4) inspect the new and the old data; 5) interpret what we hear; 6) interpolate comments and statements we hear; and 7) introspect as well as listen.

In reference to the foregoing data, it was concluded that it is important to note that there are various ways of viewing listener functions.

\section{Conditions for listening}

"Listening does not occur merely because there is a "speaker and a potential listener; certain conditions must be present in the situation.

. Rice and Ratner (1967) dealt furbamentally with the conditions for listening. They maintained that the temporal sequence of the language interaction can be roughly divided into three segments: 1) onset, 2) maintenance, and 3) termination. For listening to begin, a speaker must be identified by a potential listener and the listener must identify himself as such. 7 "They explained that the conditions required for the maintenance of listening behavior include, those necessary for its onset as well as termination. First, the listener 
cannot be a speaker at the same time, since the speaker must "pay attention" (Iisten) to his own behavior in order to maintain speech and thought flow. The listener must have some knowledge of the referent; if he does not share the same kind of referential information with the speaker, he will discontinue recording the speaker's statements.

The concurrent activity of the listener (those behaviors which occur in temporal conjunction with listening) must be primarily maintaining rather than competing (e.g., head nodding is maintaining action for listening; driving a car or reading is a competing action) (Rice and Ratner, 1967).

Another important condition for maintaining listening as stated by Rice and Ratner (1967) is the setting.

- . dangerous settings may provoke maximum statement-recording and-directing regardless of the listener's knowledge of the particular referent. When a listener begins to stroke, referential listening is not, by definition being maintained, therefore, dangerous settings are not conducive to stroking. In such situations, an increase in information about the referent may reinforce listening.

Conditions were described which are conducive to the "termination of listening," though the termination may be only momentary: the speaker may stop speaking; concurrent actions of the listener may intrude, like lighting a pipe; or the listener may either have no knowledge of the referent (foreign language) or he may have complete knowledge of the referent (description of a book he has already read).

\section{Variables Affecting Listening}

It was suggested earlier that the major characteristic 
used to identify the listener function is the manner in which the listener interacts with the statements of the speaker about the referent. According to Rice and Ratner (1967), several variables may affect this interaction, and, therefore, influence the onset, maintenance, and termination of listening. In other words, the way s speaker reacts to the listener, determines how the listening act is affected. If the speaker reacts negatively, the onset of listening will most likely be affected; and if this continues during speaking, listening may even be terminated.

In their description of variables affecting listening behavior, Rice and Ratner (1967) stated that a listener's behavior may be influenced by his past contact with a particullar speaker. They noted that a listener who is well acquainted with the speaker may modify that speaker's statement: more than if the speaker and listener are strangers. It also follows that recording beharior would be lessened. Harms (1961) conducted a study to test listener comprehension of 180 adults selected from a non-college population. There were nine male speakers aged 30 to 50 years.

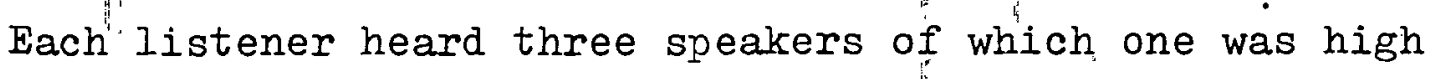
social status, one midale social status and one low social status. Each speaker was heard by 60 listeners of which 20 were'high status, 20 were middle status and 20 were 10 w status. The results indicated that listeners belonging to the "same social status as the speaker tend to have less 
trouble comprehending that speaker than one that is of a different status. It was not only found that a long history of Iistener-speaker contact may increase listening onset, but",also may increase the probability of stroking, especially if the contact is an intimate one. It was thought that if the listener-speaker contact is short or there is no history of contact, then referential listening would more than likely be difficult to maintain until the listener adapts to the personality and speech characteristics of the speaker. It also was most probable that no history of listener-speaker contact would decrease the possibility of stroking and the termination of listening. This was due to. the fact that the listener would have more difficulty predicting the referential activity of a strange speaker and relatively more accuracy in predicting referential activity. of a familiar speaker.

"Another variable mentioned affecting a listener's behavior was the history of the listener's contact with the referent. Here a relationship may result in which both no history of contact and a very long history of contact has an increased affect on listener termination. Time spent in listening also may result in an increase in time spent modifying the speaker's statements (Rice and Ratner, 1967).

A third variable related by Rice and Ratner (1967) that may have an affect on a listener's behavior is the speech characteristics of the speaker. Rice and Ratner 
(1967) cited the following references. "Rosenberg and Curtiss (1954) were mentioned as stating that stuttering depressed listener activity; Matarazza and Wiens (1964) were credited with saying that the jength of the speaker's utterances affects the listener when he later becomes a speaker; and Keller (1960), was reported to have found that a high rate of speaking tends to decrease listener compre-. hension or statement-recording.

II. DISCUSSION OF ATTENTION

One cannot examine listening or auding without considering terms such as "levels of attention," "selective attention," and "attention span." Therefore, studies and articles concerning these three terms will be summarized.

\section{Ievels of Attention}

Peterson (1969): listed three levels of attention:

1. The lowest level was labelled emission which is a class of activities characterized by self-guidance and independence from environmental cues. Examples of this level were reciting the alphabet and counting. Iittle. attention should be required to maintain such activity.

2. A higher degree of attention was postulated for activities dependent on external events for which reproductions of the event, in some sense is required. Direct correspondence between input and output Is required, but differences in coding may be present An example of this 
was reading aloud visual characters and shadowing which is simultaneously reproducing utterances of a speaker. Since a degree of uncertainty is present, in, that the input is not predictable in the way that a self-maintained. sequence is predictable, a greater degree of attention is required than the case of emissive activities.

3. A third level of attention was suggested for activities which involve some types of problem solving prior to output, so that more, than reprobuction of input is required. Examples were an arithmetic computation or an anagram solution. A relatively complex transformation "ii" of the input is required, and it was assumed that this requires a greater level of attention than the previous levels.

\section{Selective Attention}

Several stimuli may simultaneously impinge upon a person and he must select to which stimuilus, if any, he will attend. Stevens (1962), among others, has conducted studies in selective attention.

In experiments with human subjects, Stevens (1962).

found that the most important step was to tell when to "pay attention" to a restricted aspect of the stimulus. He "explained that we tell the animal to "pay attention" by differentially reinforcing two or more values of the controlling stimulus. Any aspect of the stimulus that is differentially related to reinforcement may then come to 
control the animal's behavior. Usually, more than one aspect is differentially reinforced, and the question arises which one or several of these aspects-actually controls the behavior. The experimenter may have one aspect in mind; the animal, another.

Stevens (1962) further stated that varying the stimulus in many dimensions in test trials will show which dimensions control behavior. Varying the stimulus in iall nonessential dimensions during training may eliminate in advance a dependence on undesired stimulus aspects, as 'such variation prevents particular "stimulus values from becoming correlated with reinforcement. The experiment should be simplified as much as possible by reducing the number of discriminable dimensions. Unfortunately, eliminating a dimension in this way is not always easy to do, because one must know in advance what the animal can discriminate.

Treisman (1969) stated that attention can be defined as the selective aspect of perception and response. His findings suggested:

". - division of attention between two or 'more inputs and between two or more targets is difficult or impossible, when no time is allowed for alternating "attention or serial analysis, and that selective focusing is both efficient and frequently used with inputs reaching a single analyzer from different

iphysical sources or with target items identified by the same analyzer or by overlapping groups of shared analyzers.

He (Treisman, 1969) noted, however, that experiments 
requiring attention to different dimensions were less conclusive, because
- - experiments testing focused attention have often assumed that divided attention is impossible and looked for perceptual interference from irrele- vant analyzers, while experiments testing divided attention have often assumed that focused attention is possible and measured decrements with divided attention. The evidence on the whole suggests that focusing on a particular dimension is difficult, at least when it involves selecting one of two inde- pendent aspects of a single set of stimuli (e.g., when it cannot be combined with input-selective attention), while division of attention between analyzers is relatively efficient at least compared to division of attention between inputs.

He (Treisman, 1969) provided an example which may be helpful in clarifying the above quotation. An observer may be in a situation of over-hearing two conversations about the same topic. It would be most difficult for the observer to focus attention on one of these speakers. On the other hand, if there were two simultaneous conversations about two totally different topics the observer would have less difficulty focusing his attention on one of the conversations.

In his paper, Treisman (1969) reviewed experiments on selective attention, mainly to competing speech messages, and related them to Broadbent's (1958) filter theory. Four types of attention strategy were distinguished: The first restricts the number of imputs analyzed; the second restricts the dimensions analyzed; the third restricts the items (defined by sets of critical features) for which subjects are listening; and the fourth selects which results of perceptual analysis will control behavior and be stored in 
memory •

Clifton and Bogartz (1969) stated that Broadbent's "selective attention" referred to a single "communicative channel," and that messages arrive to a person by various communicative channels. Any attribute of a message has the potential for specifying a channel.

For instance, a message's attribute of being visual can be used to specify a communicative channel. And, the attribute of being presented to the right ear, or of being high in pitch, can be used to specify particular auditory communicative channels.

According to Broadbent (1958), people receiving messages were able to filter out those messages arriving by certain channels, so that the messages transmitted to these channels were attenuated.

A person rejects, to some incomplete extent, a message transmitted on the filtered channel, and does not process (e.g., make an immediate reaction to, or store in memory), all aspects of the message. This ability to filter out the messages transmitted on certain channels accounts for the putative ability of receivers to concentrate on a single message at one time (Clifton and Bogartz, 1969).

There has been acceptable experimental evidence that adult listeners are able to attend to messages transmitted on one channel, while largely ignoring the messages coming in on other channels (Treisman, 1964).

Clifton and Bogartz (1969) found data reported by Maccoby and Konrad (1966) indicating that

- . kindergarten children can selectively recall a message in one channel, when the channel is defined by the sex of the person speaking the message. Their 
data, however, do not allow the conclusion that messages in other channels are actually attenuated. In a subsequent study, Miaccoby and Konrad (1967) obtained evidence that children selectively recall a message in one channel more effectively when the channel to which response is demanded is identified before the message is transmitted than when it is identified after the message.

This result suggested the conclusion that the irrelevant channel was filtered by the listener when it was identified prior to the transmission of the message.

Maccoby and Konrad's study, as reported by Clifton and Bogartz (1968), attempted to provide a demonstration of childrens' selective attention to messages transmitted via a particular channel. Subjects were given an auditory short-term memory task in which remembering material presented to one ear (channel) was consistently rewarded, while remembering material presented to the other ear was never rewarded.

Extended training on this task might be expected to result in attenuation of the messages presented to the nonrewarded (irrelevant) ear, and thus selective attention to the relevant ear, in that attenuation of the messages presented to the irrelevant ear would reduce the amount of material $S_{S}$ would have to remember on each trial. To test for such selective attention, several test trials were given toward the end of the experimental session on which $S_{S}$ could con-. sistently respond correctly only by attending to and remembering the messages presented to the previously irrelevant ear were attenuated, poorer performance would be expected on these trials than on adjacent trials testing memory for items presented to the ear that was consistently relevant earlier (Clifton and Bogartz, 1968).

Span of Attention

Attention span is a third important aspect of attending 
behavior. In an article by Powers (1969), he stated that contemporary literature suggested that the concept of attention span refers to two different phenomena. English and English, cited in Powers (1969), listed under span of attention: "(a) The number of distinct objects that can be perceived in a single momentary presentation; and (b) the length of time a person can attend to one thing." The length of time a person can attend to one thing was referred to as voluntary attention by James in 1890 and by Angell in 1904. Subsequently, the length of time a subject concentrated on a task has been referred to as perseveration by Cushing in 1929, interest span by Herring and Koch in 1930, sustained attention by Schacter in 1933, and as attention span by Botte in 1928; Van Alstyne in 1932; Cockrell in 1935; Gutteridge in 1935; Moyer and van Haller Gilmer in 1955 (Powers, 1969).

History of early work on the span of attention was given in a concise manner by Whipple in 1924, and Garrett and Schneck in 1933 (Stevens, 1962).

According to Powers (1969), the concept of attention span seemed to be used currently in at least three ways: 1) empirical evidence indicates that "attention span" is task specific; 2) many authors have given the impression that short attention span, distractibility, and hyperactivity refer to different phenomena, differences among the behavioral referents of these concepts are often 
difficult to specify; and 3) attention span is sometimes discussed as though it were an inherit power or ability and the observed behaviors of distractibility and hyperactivity are the result of an underlying short attention span.

"An operant conditioning analysis of attention span suggested an alternative view (Powers, 1969). The most important, single principle of operant conditioning is the empirical principle of reinforcement. The principle refers to the "observation that there are certain "environmental events; that are commonly called rewards, and to make a behavior more frequent, it is subsequently rewarded. These s... rewarding events are more technically referred to as reinforcers. A reinforcer was defined as a stimulus, the presentation of which, following" a response, increases the probability of future occurrences of the response (Powers, 1969).

He stated that several variables are crucial to the success of the reinforcement procedure. The first was the contingent relationship between the response and the reinforcer. The contingency is a logical if-then relationship, which is to be distinguished from a simple pleasant or rewarding situation in which a person might find himself. This is mainly due to the reinforcement procedure which requires the occurrence of some specified response prior to the presentation of a reinforcer and a pleasant situation 
does not. The second crucial variable was the immediacy of reinforcement. To be effective, the reinforcer must follow the response without delay (Powers, 1969).

Working within the framework of operant conditioning, the term "attention span" referred to nothing more than the behavioral events to which the name is attached. These behavioral events were explained in terms of environmental variables in the presence of which theibehavior occurs.' This interpretation emphasized behavior that interfere with attending to a task, as well as attending behavior itself.

He (Powers, 1969) summarized that a long attention span is the result of presenting reinforcement contingent upon attending behavior, and not reinforcing behavior that is incompatible with attending. Short attention span can be observed when reinforcement is contingent upon behavior. that is incompatible with attending, and not reinforcing the attending behavior.

III. CHARACTERISTICS AND MEASUREMENT OF IISTENING

Ten Characteristics of Good and Poor Listeners

Nichols and. Lewis (1954) noted that research completed at Michigan State College, Stephens College, Florida State University and the Universities of Iowa, Missouri, Minnesota, and Denver made it possible to be more explicit in devising training programs to improve listening comprehension. Based on the results of these studies, ten components of effective 
listening were identified which made it possible to clarify at least ten important characteristics "of the good and poor listener.

These ten characteristics of good and poor listeners were as follows:

1. Previous Experience with Difficult Material. The inexperienced listeners are the poorest listeners of all. They are inexperienced in hearing material that is difficult in nature. These listeners have a tendency to spend their leisure time listening to or watching purely recreational programs on the radio or television Good listeners, however, seem to take advantage of the more difficult radio and television programs that tend to challenge their mental capacities.

2. Interest in the Topic at Hand. It has been noted. in many objective studies concerning listening, that the interest factor in "aural assimilation" is of tremendous significance. Good listeners seem to be able to find elements of interest in almost all topics of discussion; on the other hand, poor listeners are frequently bored and find the topic uninteresting or "dry." These poor listeners have undoubtedly developed the bad habit of condemning a topic as uninteresting without putting effort into finding something of interest.

3. Adjustment to the Speaker. Every speaker has his peculiarities, some more noticeabie and distracting than 
others. "It is natural for the listener to note the speaker's! peculiarities; however, the poor listener. has a tendency to become preoccupied by them and, eventually, to use them as a rationalization for following some "mental tangent rather than the speaker's subject matter. Helis, in fact, throwing the entire responsibility for communication upon the speaker which is a serious listening fault. "No more than half such responsibility, at most, can logically be placed upon the conveyör."

Nichols (1948) found objective "evidence that the Iistener's attitude toward the speaking characteristics of the conveyor influence the efficiency of oral communication. In a later publication (Nichols and Lewis, 1954) he writes:

Communicative efficiency is strongly affected by the audibility of the speaker and by the listener's estimate of the propriety of the language being used. Communication is less strongly, but still consistently, affected by four other such factors: admiration for the speaker, estimate of his overall effectiveness, amount of high school speech training received by the listener, and the listener's personal susceptibility to distraction.

Good listener's, when afflicted with a weak speaker, if

will give their conscious and overt attention to him. They realize that the speaker and the audience share responsibility for the success or failure of communication. They, therefore, assume not less than half of the obligation for communication. On the other hand, "poor listeners slight their fair share of the task, and hold the conveyor singly responsible for holding their attention." 
4:- Energy Expenditure of the Iistener. Although efficient listening is considered the simplest way know to obtain ideas and information, it is still hard work. "It is characterized by increased heart action, faster. circulation of the blood, and even slightly, increased bodily temperature." It was noted that an outstanding characteristic of poor listeners is their unwillingness to expend energy in a listening situation. "They also seem to be unchallenged by the physical demands that are made upon them when confronted with a listening situation. They tend to "fake attention" which is considered to be "... one of the surest of all indices to low-level comprehension -." and ". . one of the worst habits afflicting us as a people."

5. Adjustment to the Abnormal Listening Situation. Another definite difference between good and poor listeners is the way they react in abnormal listening situations. It has been noted, for example, that good li!steners tend to make quick adjustments to ". . poor room ventilation or temperature, inaudibility of the speaker, personal hearing disabilities, unnecessary room noises which distract attention, and noisy neighbors or seatmates in the audience." In contrast to this, poor listeners ". - tendito tolerate all of the above conditions and in some instances, even to create distractions themselves which neediessly impair comprehension." 
6. Adjustment to Emotion-Laden Words. To be a good listener one must make adjustments to" "emotion-laden words." "This is accomplished through a careful examination of the words that arouse emotion within him as a listener. This "examination will most likely reveal that such words really should not bother one at all. It has been found that poor Iisteners are frequently aroused emotionaly which seriously handicaps their ability to reason. Goodisteners, on the other" hand, are more objective-minded and analytic enough "to be"little affected.

"7. Adjustment to Emotion-Rousing Points. The adjust-" ment to emotion-rousing points is more difficult to overcome. than to emotion-laden words, largely because of their greater duration. In both situations the damage is done "through "over-stimulation." "Good listeners tend to wait until they fully understand a point before attempting to "judge it." As mentioned previously, poor listeners have Iess emotional control and may develop an intense dislike for $a$, speaker early in his speech because of some minor point he made. This dislike'may result in an over-eagerness: to debate or annoy the speaker which is a common product of faulty comprehension. "They consistently prepare an answer to a point, or question about it, before the point itself is "fullyi comprehended."

8. Recognition of Central Ideas. "Good listeners have an ability to focus on central ideas and they can usually 
recognize the characteristic language in which central ideas are commonly stated. They also have the ability to discriminate between ". . . fact and principle, idea and example, evidence and argument." The poor listeners lack these discriminating abilities and may take pride in the statement that they "listen for the facts" in every presentation.

9. Utilization of Notes. An important component of effective listening is skill in the "utilization" of notes taken during lectures. Note-taking can either aid the learner or can hinder the learner by becoming a distraction itself. It is a well known fact that the more notes we take the more hearing time is replaced with writing time. The mere accumulation of notes is not considered a scholarly act. A good listener may set aside a period in the day to go over notes taken during that day. This is a most effective way of incorporating the new facts and ideas received. 10. Reconciliation of Thought Speed and Speech Speed. Concentrating by the listener is influenced by two variables, largely beyond his control: ". . his own speed of thought and the rate of speech of the communicator." This last component of effective listening is the most important of them all. It requires the listener to reconcile his thought speed and the speaker's speech speed. "By reconciliation of thought speed and speech speed is meant the utilization of the differential between them to expedite comprehension 
and learning." It should not be attempted. to synchronize their rates.

,

Although Nichols and Lewis (1954) cilearly identified ten characteristics of good and poor listeners, they did not devise an objective test for measuring them. One does hot know how and when the college student develops good and poor listening habits.

They (Nichols and Lewis, 1954) also, "hypothesized that college speech classes, in general, "teach" students to isten more skillfully either directily or indirectly. They did not administer a formal test, to college students to verify this theory. ,

\section{Nieasurement of Iistening Behavior}

Measurement of listening behavior is the final step for bringing the listening aspect of the language interaction under experimental investigation. "One method is to äsk the listener what he has been doing. This can be done informally or by testing his comprehension of either the speaker's statement or the referent (Rice"land Ratner, 1967). Bakan (1967) felt that tests of listening "should be conducted so the subject is unaware he is being tested; hence, he is less likely to rehearse. Another method of measurement is to observe subsequent:listener activity. The subject can be observed interacting with objects, or he himself may become a speaker, and the-degree of statement-modification can be observed. (Rice and Ratner, 1967). What might

$$
\text { is }
$$


appear to be statement-modification, however, may be an error in statement-recording, and this must be controlled. A third method of measurement is to record physiological changes in the listener during the language interaction and correlate these with psychological changes. Brown (1967) in 1962 found no differences in breathing rate between "good" and "poor" listeners, though he did find that all listeners tend to adjust their breathing rate to coincide with that of the speaker's. Rice and Ratner (1967) discussed measurement when they stated the following:

Measurements which will discriminate the different listener functions are paramount. It may be, for example, that different kinds of listener concurrent activities occur during different listening functions, so that a listener may nod and grunt during statementrecording, but raise his finger or look away during statement-modification. Or it may be that the listener displays the same behavior in different amounts during different kinds of listening functions, so that a listener may sit quietly during statement-recording, display more concurrent actions during statementmodification. For the latter kind of measurement, of course, it would be necessary to first determine the listener's operant rate of activity.

The phrase "listener's operant rate of activity," referred to the time it takes a listener to react to a particular act of communication.

\section{Tests of Listening}

Duker (1966) cited the following tests designed to measure what he calls "listening ability" which considers individual differences.

The first test specifically designed to test listening 
ability was an unpublished test developed by Paul T. Rankin in 1.926.

The first published test designed to measure listening" was the Durrell-Sullivan Reading Capacity Test which was first published in 1937 and is stili in use. It was designed for the second through the sixth grades.

In 1953 the Brown-Carlsen Listening Comprehension Test was published. It was designed for the secondary level as well as for the first year of college, but has been. used at all. levels in college and also in business and industry. It has been widely used and has been the subject of much research.

In 1957 the Educational Testing Service of Princeton; New Jersey, published the Sequential Tests of Educational. Progress, commonly known as the STEP test. 'A listening test was included. It is on four levels and is recommended for grades four through fourteen.

These are some of the tests that have been developed and are still extensively used today. The most popular are the STEP and the Brown-Carlsen Listening Comprehension Test. As mentioned earlier, no test hasi been developed to. test good and poor listener aptitude. "This writer devised: such a test utilizing the ten characteristics identified by Nichols and Lewis (1954). The Brown-Carlsen Listening Comprehension Test (1953) was used to validate test items. Much of the survey of the literature includes theories 
The purpose of this chapter is to describe the experimental design. The following topics will be presented to facilitate the description: the test instruments, the procedures and methods used, and data analysis measures.

Initially, a test referred to as the listening Attitude Test (IAT), was developed in order to measure conceptual changes in listening skills. This test was then presented" to three different student populations: 1) students who had just completed Speech 100 or $111 ; 2$ ): students "who were a year removed from Speech 100 or 111 ; and 3) students who have never had Speech 100 or 111. All of the students from these three populations were selected. from Speech 100, Speech 111 and English Composition classes at Portland State University.

After completing the LAT, the subjects who met criteria "were selected from each population." Their tests were scored and the following statistical tests were then appinied to the data, where appropriate, in order to furnish the statistical implications. An Inter-item Correlation Matrix of the total population was performed. This was followed by a Pearson Product-moment Correlation Coefficient 
performed on the IAT with Parts $A, E$ and $A$ and $E$ combined of the Brown-Carlsen Test. Then a $t$ test was administered to the three populations that took the LAT.

\section{THE TEST INSTRUMENTS}

Listening Attitude Test. This test was designed by this researcher to measure conceptual changes in listening skills. The IAT was developed from the ten components of effective listening found in Nichols and Lewis (1954) and was administered to Speech 100, Speech 111 and English Composition students. There was a Part A and a Part B to each of the twelve questions asked and students were to answer by circling one of five choices. The choices were: $A$, strongly prefer statement "A" over statement "B"; $a$, somewhat prefer statement "A" over statement "B"; ?, both statements are equally acceptable to me; b, somewhat prefer statement "B" over statement "A"; or $B$, strongly prefer statement "B" over statement "A" (see Appendix A).

The LAT and the Brown-Carlsen Listening Comprehension Test, Parts $A$ and $E$, were then administered to English Composition classes at Mt. Hood Community College as part of a pilot study (see Appendix B). The results were then used to standardize the Listening Attitude Test.

After the standardization and the administration of the Inter-item Correlation Matrix, six questions were found to be statistically significant (see Appendix C). They are 
Question 1: A. There is something of interest in almost every speech or lecture that I hear.

B. It is rare, indeed, when I hear a speaker who can really interest me.

Question 2: A. Many of our best ideas are triggered by speeches and lectures.

B. Few of our best ideas are triggered by speeches and" lectures.

Question 6: A. If a speaker does not communicate his ideas clearly, it is usually a waste of effort to continue listening closely.

B. Speakers that are difficult to understand at first, are often the source of the most valuable ideas.

Question 8

A. When I miss the first part of a speech or lecture, I usually am impatient to find out what the speaker said before I arrived.

B. When I miss the first part of a speech or lecture, I am usually bored to tears throughout the part that I do hear.

Question 10. A. I get the most out of a speech or lecture when I relate it to things that the speaker does not discuss.

B. I get nothing out of a lecture when a speaker fails to relate it to familiar ideas.

Question 12. A. I know from his first few comments whether or not I care to hear any more from a speaker.

B. I have difficulty assessing the value of a speech or lecture until it is over.

The preferred answers to these questions are: question: 
one is $A$; question two is $A$; question six is $B$; question eight is $A$; question ten is $A$; and question twelve is $B$. These six significant questions were then considered to be testing what they purport to test, which is listening attitude. They were then administered to the Portland State University populations.

Brown-Carlsen Iistening Comprehension Test. This test purports according to Brown and Carlsen (1953), to measure "the ability of students to comprehend spoken language." Iistening comprehension is defined as the "aural assimilation of spoken symbols in a face-to-face speaker-audience situation, with both oral and visual cues present" (Brown and Carlsen, 1953). There are two Forms, Am and Bm, the former is comprised of 76 test items and the latter of 96 items. These items are grouped into five subtests:

A. Immediate Recall, which measures the ability to keep a sequence of details in mind until a question is asked which requires thinking back over the sequence; $B$. Following Directions, which measures the ability to follow oral directions; C. Recognizing Transitions, which measures awareness of the function of transitional words and phrases within sentence contexts; D. Recognizing Word Meanings, which measures the ability to recognize meanings of words from context; and $\mathrm{E}$. Lecture Comprehension, which measures the ability to listen for details, get the central idea, draw inferences, understand the organization, and note degree of relevancy in a brief lecture presentation read by the examiner (Brown and Carlsen, 1953).

For the purpose of the present study, Form Am, Parts $A, E$ and $A$ and $E$ combined (Immediate Recall and Lecture Comprehension) was used as the standardization tool for the 
LAT. Parts $A$ and $E$ were chosen because it was felt they measured listening skills similar to what the IAT was purporting to measure.

The validity and the difficulty âs well as reliability data for test items in the Brown-Carlsen Listening Comprehension Test, Form Am are listed in Appendix D.

II. THE PROCEDURES AND METHODS USED

Subjects

Age. Students were eliminated from the study if they were over twenty-one years of age and above sophomore status. The purpose of this was to control the age variable and listening experience variable:

Sex. The sex variable was not controlled due to the difficulty of obtaining a sufficient sample.

Selections. The samples were selected from Speech 100, Speech 111 and English Composition classes at Portland State University during the Fall of 1970. The population was stratified by selecting equivalent numbers of students with the same amount of college experience. There was approximately 200 students participating, depending on the enroliment of the classes involved in the "study. Students were eliminated if they had attended other. speech classes either in high school or college.

* Description of Groups Studied. The Group I sample, Who had not attended an introductory speech communication 
course (Speech 100 or 111) was taken from the first sequence of English Composition (Eng. 121).

The Group II sample who had just completed an introductory speech communication course, was taken from selected "Speech 100 and Speech 111 courses during the last two weeks of the term. Group I and II. students were just completing their first terms as freshman or sophomores in college. The Group III sample, who had an introductory speech communication course, but was approximately one academic year removed from it, were taken from the second and third Sequence of English Composition (Eng. 222, and 323). "Students from this group had to be in their sophomore year. English Composition students were selected because they represented the best cross-section of students of the desired age group at Portland State University. There also Was a high probability that there would be students who had taken Speech 100 or 111 enrolled in an English Composition course.

In summary, female and male student's, between eighteen" and twenty-one years of age and not above sophomore status were selected from Speech 100, Speech 11 and English Composition classes at Portland State University during the Fall of 1970. These students were divided into three popula"tions: Group I and Group II ranged from "beginning freshman to beginning sophomores; Group III ranged from first term to last term sophomores. 
III. ADNINISTRATION OF TEST INSTRUMENTS

In the process of developing a listening attitude test, the investigator and an assistant was required. The assistant was a person with oral interpretation training. This person was needed to record the directions to Parts $A$ and $E$ of the Brown-Carlsen Listening Comprehension Test (Brown and Carlsen, 1953) on tape. The Brown-Carlsen test was used to standardize the Iistening Attitude Test and a tape recording was used to minimize variability (see Appendix E).

The examiner's job was to introduce himself or herself and the study from a prepared speech that would not influence the test. After the introduction the examiner then read the directions to the Ilstening Attitude Test outloud while the students read along silently. If there were no questions, the students immediately took the test (see Appendix $F$ ).

The tests were administered the second to the last week of Fall term, 1970. The reason for this, was that one of the populations had to be tested near the completion of Speech 100 or 111 before they dispersed. All students were tested during the week prior to finals for that term. Those students that were over twenty-one years of age were eliminated from the study to control age. Experience was controlled by limiting potential subjects to freshman and 
sophomore class students.

There were several Speech 111 courses offered and one Speech 100 course offered, therefore, students used in the study were selected from the above mentioned basic speech classes taught that term. By way of clarification either course is considered an introductory course in general speech.

Another variable to control was the possibility that il students in the study may have had previous exposure to "Iistening instruction. On the form to be completed by the students before taking the Iistening Attitude Test, the following questions were asked: Have you had any high school speech courses? Have you had Speech 100 or Speech 111 in college. If so when? Have you had any other college ispeech course(s)? If so, describe briefly. The students were not used in the study if they answered positively to any question other than Speech 100 or 111.

The tape recording used in administrating the BrownCarlsen Listening Comprehension Test was of good quality so students could easily hear and understand what was being said

IV. DATA ANALYSIS

"The statistical tests performed, where appropriate, were as follows: 1) An Inter-item Correlation Matrix of the total population (see Appendix C); 2) a Pearson Product- 
moment Correlation Coefficient; and 3) a t test.

An Inter-item Correlation Matrix was performed to

determine if each IAT question was answered significantly different than another question. Atrong positive correlation means a favorable correlation exis"t between questions, and" that two questions are not answered significantly different. A negative correlation means that two questions were answered significantly different.

A Pearson Product-moment Correlation Coefficient was performed to determine if the results on the LAT and the Brown-Carlsen Test, Parts $A, E$ and $\dot{A}$ and $E$ combined would correlate significantly. If the results correlate strongly, it would be assumed that the IAT and the Brown-Carlsen Test, Part's $A, E$ and $A$ and $E$ combined were testing similar skills. The Pearson $r$ was applied to the Listening Attitude Tests and the Brown-Carlsen Test Parts given to the Pilot study. group only,

The $t$ test was then administered to the LAT results of three different student populations. Each of the three student groups were compared with the other student group. The results determine if the performance between two groups are statistically significant departures from chance at the .05 level of confidence. 
CHAPTER IV

RESUITS AND DISCÜSSION

I. RESULTS

The purpose of this chapter is tolpresent the results of the study. In the Statement of the Problem, three questions were raised. These questions will be repeated to introduce the statistical results; the latter part of the chapter will be devoted to a discussion of the findings.

Initially, the Listening AttitudejTest (LAT), which tests the ability or skill of recognizing good listening habits was developed. The IAT was then correlated with the Brown-Carlsen Listening Comprehension Test Parts A, E and A and $E$ combined.

A Pearson's correlation proc"caure was used to compare the possible relationship between the IAT and the BrownCarlsen Test Parts mentioned above. The correlations revealed a strong positive relationship between the LAT and Part $E(r=0.65)$ and the LAT with Parts $A$ and $E$ combined $(r=0.63)$. Both were statistically significant beyond the .005 level of confidence.

In analyzing the relationship between the IAT and Part A of the Brown-Carlsen Test, the Pearson's correlation procedure also was used. The correlation with Part A, not 
interacting with Part $\mathrm{E}$, was low $(r=0.03)$ and was not found to be statistically significant; however, since Part $\mathrm{E}$ and Parts $\mathrm{A}$ and $\mathrm{E}$ combined correlated well, the investigator concluded that the IAT was testing what it purported to test, i.e., Iistening attitude. Appendix.G contains a summary of the raw data used for completing the correlation of the IAT with the Brow-Carlsen Listening Comprehension Test Parts $A, E$ and $A$ and $E$ combined.

The LAT was administered to three different student populations. These populations were compared by means of at test. The t test was utilized to statistically evaluate the data in order to answer the questions raised in this study. Three questions will follow with the statistical results

Question 1. Will there be a significant difference in the conceptions of listening "skills between students who have not had Speech 100 or Speech 111 and those who have just completed speech 100 or 111 Fall term, 1970?

The obtained t test was 0.09 which indicates no significant, difference.

Question 2. Will there be a difference in the conceptions of listening skills between students who have just completed Speech 100 or 111 Fall term 1970 and those who have completed Speech 100 
or 111 but are at least an academic year removed from it?

The obtained $t$ test was 1.82 , which is significant beyond the 0.05 level of confidence (one tailed test).

Will there be a difference in the conceptions of listening skills between students who have not had Speech 100 or Speech 111 and those who completed Speech 100 or 111 but are at least an academic year removed from it?

The obtained t test was $1.80^{\circ}$ which is significant beyond the 0.05 level of confidence (one tailed test).

\section{DISCUSSION}

In support of the general conviction that individual listening skills improve when taught in a speech class, one might consider the following possibilities as influencing the results of question number one.

The results indicated that there was no significant difference between the students who had just completed the Speech 100 or 111 course and the students who had never had: the Speech 100 or 111 course. It would seem that if 1 istening skills were taught, the population that just completed the speech 100 or 111 course would perform better on the IAT test. The data, however, seems to indicate that this is not the case. When considering the literature on 
human learming, (Osgood, 1953; McGuire, 1960) there is some evidence that a test for performance skills should not be administered to students until they have had time to assimilate the concepts. A delayed test, in other words, would prove to be more valid than a test requiring immediate recall or execution.

When applying, the human learning theory to the results found in question one, it may be that the Speech 100 or 111 course did teach listening skills, but since latency improves performance skills, they had not appeared as yet. If the just completed students had been tested a few days later, a significant difference might have been found.

On the other hand, when interpreting the results of question one, nonsupportive implications existed. The never had Speech 100 or 111 students were composed of both freshman and sophomores and the just completed Speech 100 or 111 were composed of only freshman. Although age was controlled in the study, perhaps those who were sophomores became sophomores through "survival of the fittest." In other words, the experience factor of the sophomores could have influenced the test results enough to improve that populations' scores to the extent that there was very little variation between the two populations' scores to show a significant difference. This interpretation supports the hypothesis that listening skills are taught through school experience rather than through a speech class. 
It also was noted that the teaching of listening was not well defined in the Speech 100 and 111 curricula, i.e., there appeared to be no specific unit on listening nor specific training in the application of listening skills. One might conclude, therefore, that concepts indirectly or randomly taught did not generalize enough to result in a good performance on the IAT.

The following possibilities might be considered as influencing the results to question number two. As the results showed, there was a significant difference between students who have just completed the Speech 100 or 111 course and the students who were at least one academic year removed from completing the Speech 100 or 111 course. This could be interpreted to mean that the Speech 100 or 111 course acted as a trigger to the development of listening attitude skills. This supports the human learning theory which indicates that performance skills improve when the administration of the test is delayed.

Another consideration, is that the year's experience of applying the listening attitude skills taught in Speech 100 or 111 course could have developed further listening attitude skills not covered in the Speech 100 or 111 course which resulted in better scores. There is also the possibility that listening attitude skills were taught, but were not fully understood or developed until they had been applied for a year. 
If one interprets the results to question two in a nonsupportive manner of the value of an introductory speech class to the teaching of listening skills, it should be pointed out that the year removed population might possibly have learned listening attitude skills not so much from Speech 100 or 111 courses as from the composite experlences of the ensuing year. Since these subjects had not been enrolled in other speech courses that would serve to refresh or improve their listening attitude skills, no influences other than experience would be present; therefore, it would seem likely that the population that had just completed Speech 100 or 111 courses would perform better because their information would be more current. As the results suggested this was not the case, which indicates that listening attitude concepts were not learned as a result of the Speech 100 or 111 courses, but were developed instead as a necessity to survive in college.

Lastly, when considering question number three, the results indicated there was a significant difference between students who were at least one academic year removed from completing the Speech 100 or 111 courses and the population who had never had the courses (Speech 100 or 111 courses). In support of the general conviction that listening skills improve when taught in a speech class, the following possibilities might be considered as influencing the results of question number three. In the literature, Nichols and 
Lewis (1954) have observed that exposure to college speech courses facilitates listening skills. The above results of question number three support Nichols and Lewis' statement. Again, the latency theory can be lapplied here by. stating that Speech 100 or 111 did teach listening skills, but understanding did not appear until a year later on a delaỵed test.

In summary, the results basically revealed that, whether presently taking the course or not, the students performed differently than the year removed students. This difference may be due to various influences such as time in school, exposure to a speech class or time to assimilate and apply information learned about listening in aspeech class.

It is clear that the findings support those contending that exposure to speech improve listening skills. The claim made by Nichols and Lewis (1954) that instruction in 'listening skills would improve listening was not supported by the "just completed group" data and no single overriding hypothesis seems to account for this discrepancy. Nichols and Lewis (1954), however, were dealing with college hspech courses which were heavily loaded with training techniques for improving listening ability, which was not the case in Speech 100 or 111 courses at Portiand State University. 


\section{CHAPTER V \\ SUMMARY AND INPLICATIONS FOR}

FURTHER RESEARCH

\section{SUMMARY}

The purpose of this study was to determine the impact fof collilege speech classes upon developing improved listening skills. More specifically, it sought to determine the exthent to which the students who took speech 100 or 111 have acquired listening skills.

"acquit: distening skilis.

There has been considerable theorizing concerning listening and auding with only a scattering of experimentation. According to existing data, listening would appear to be a complex human behavior that is only partially under"stood: There are, however, definite listener functions, Iistening conditions and variables that affect listening. Aspects of attention are also important when considering the occurrence or nonoccurrence of listening. Initially, the Iistening Attitude Test (IAT) was developed in order to measure conceptual changes in listening skilis. The IAT was statisticaliy analyzed to determine Its validity. This test was then presented to three different'student populations: 1) students who had just completed Speech 100 or 111; 2) students who were at least one 
academic year removed from Speech 100 or 111; and 3) students who have never had Speech 100 or 111. All of the students from these three populations were selected from Speech 100, Speech 111 or English Composition classes at Portland State University. The performance of the three populations were statistically compared using the $t$ test to determine the significance of differences between means. The following is a summary of the findings. The IAT was correlated with the Brown-Carlsen Iistening Comprehension Test Parts $A, E$ and $A$ and $E$ combined. The results indicated that the IAT was testing what it purported to test, i.e., listening attitude. The $t$ test was applied to the data from three different student populations who took the IAT. The results indicated that there was no statistically significant difference between students who have not had Speech 100 or 111 and those who have just completed Speech 100 or 111. There was a significant difference between students who have just completed Speech 100 or 111 and those who have completed Speech 100 or 111 but are at least one academic year removed from it. In addition, a significant difference was revealed between students who have not had Speech 100 or 111 and those who completed Speech 100 or 111 but are at least one academic year removed from it.

It is clear that the findings support those contending that exposure to speech improve listening skills. The claim 
made by Nichols and Lewis (1954) that instruction in listening skills would improve listening, was not supported by "the "just completed group" data and no single overriding "hypothesis seems to account for this discrepancy. Nichols and Iewis (1954), however, were dealing with college speech Heourses which were heavily loaded with training techniques for improving listening ability, which was not the case in Speech 100 or 111 courses at Portland State University. a to determine the possible influence general experience might have on the "never had Speech 100 or 111" population. They could be compared separately to the students who just completed Speech 100 or 111 and to the students who were at least an academic year removed from Speech 100 or 111. 2. Seniors who are three years removed from Speech 1 to or "111 could be compared with another group of sentors who have never had Speech 100 or 111. The results would reveal if listening concepts can be retained over a period of three years. 
3. The seniors who are three years removed from Speech 100 or 111 also could be compared with the original group (freshman and sophomores) that never had Speech 100 or 111 used in this study, to see if there is a difference. 4. It would be of interest to compare each of the four class levels in college. There would be four groups, freshman would be compared with freshman, sophomores with sophomores, juniors with juniors and seniors with seniors. The just completed Speech 100 or 111 and the never had Speech 100 or 111 would be used in order to determine if a difference in listening skills exists within each class.

5. Another possibility would be to compare freshman with sophomores, freshman with juniors, freshman with seniors, sophomores with juniors, sophomores with seniors and juniors with seniors. All groups would have completed the IAT and would not have had Speech 100 or 111. This might indicate if college attendance teaches listening skills. The above types of studies would reveal if listening skills are learned through exposure to speech or through experience in college.

A specific unit on listening skills was not a part of the speech classes used in this study. A follow up study, therefore, comparing three methods of teaching listening skills might yield valuable information. The methods would be concerned with 1) a unit on listening theory, 2) a unit on application of listening skills and 3) no specific 
unt on listening.

As a final suggestion, it would seem important to know college speech teacher's listening attıtude. It is suggested that the IAT be administered to college or university speech instructors.

To expand the above suggestion it would be interesting to compare college speech instructor's performance on the IAT with the performance of their class on the IAT. 


\section{BIBIIOGRAPHY}

Angell, J. R. Psychology. New York: Henry Holt, 1904.

Baird, A. C. and Knower, F. H. General Speech: An Introduction. New York: McGraw-Hill, 1949.

Bakan, Paul. "Some Reflections on Listening Behavior," Journal of Communication, 6:108-13, Autumn, 1956.

Barbe, W. B. and Myers, R. M. Cited within Petrie, C. R. $\mathrm{Jr}$. "What is Listening," An Experimental Evaluation of Two Viethods for Imoroving Listening Comorehension Abilities, Purdue University Doctorial Thesis, 1961.

Berlyne, D. E. Conflict, Arousal and Curiosity. New York: McGraw-Hili, 1960.

Berne, Eric. Games People Play: The Psychology of Human Relationships. New York: Grove Press, Inc., 1964.

Broadbent, D. E. Perception and Communication. New York: MacMilian (pergamon), 1958.

Brown, C. T. "Introductory Study of Breathing as an Index of Iistening," Speech Monographs, 29, 1962.

Brown, Don. Cited within Petrie, C. P. Jr. "What is Iistening," An Experimenta.l Evaluation of Two Methods for Improving Listening Comprehension Abilities, Purdue University Doctorial Thesis, 1961.

Brown, J. I. "The Construction of a Diagnostic Test of Listening Comprehension," University of Colorado Doctoral Thesis, 1950.

Brown, J. I. and Carlsen, G. Brown-Carlsen Listening Comprehension Test: Manual of Directions. New York: Harcourt, Brace and Worla, Inc., 1953.

Caffrey, John. Cited within Petrie, C. P. Jr. "What is Listening," An Experimental Evaluation of Two Methods for Improving Listening Comprehension Abilities, Purdue University Doctorial Thesis, 1961.

Carmichael, I. Manual of Child Psychology. New York: John Wiley and Sons, 1946. 
Cherry, E. C. "Some Experiments on the Recognition of Speech With One and With Two Ears," Journal of the Acoustical Society of America, 25:975-979, 1953.

Clifton, C. Jr. and Bogartz, R. S. "Selective Attention During Dichotic Listening by Preschool Children," Journal of Experimental Child Psychology, 6:483-491, 1968.

Cooperative Sequential Tests of Educational Progress Listening. Princeton, New Jersey: Educational Testing Service, Cooperative Test Division.

Cooper, S. F. "The Effect of Brightness in the Range of Attention Experiment," American Journal of Psychology, 40:254-274, 1928.

Cushing, H. M. "A Perseverative Tendency in Preschool Children; a Study in Personality Differences," Archives of Psychology, 108, 1929.

Dallenbach, K. M. "Attention," Psychological Bulletin, $25: 493-512,1928$.

Dallenbach, K. M. "Attributive vs. Cognitive Clearness," Journal of Experimental Psychology, 3:183-230, 1920.

Duker, S. Listening: Readings. New York and London: The Scarecrow Press, Inc., 1966.

Egan, J. P. "Articulation Testing Methods," Laryngoscope, 58:955-991, 1948.

Fessenden, S. A. "Levels of Listening - A Theory," Education, 75:288-291, January 1955, The Bobbs-Merrill Company, Inc., Indianapolis, Indiana.

Festinger, I. and Maccoby, N. "On Resistance to Persuasive Communications," Journal of Abnormal and Social Psychology, 68:359-366, 1964 .

Fletcher, H. Speech and Hearing in Communication. New York: Van Nostrand, 1929, Reprinted in 1963.

Freedman, J. I. and Sears, D. O. "Warning, Distraction, and Resistance to Influence," Journal of Personality and Social Psychology, 1:262-266, 1965.

Guthrie, E. R. "Association by Contiguity." In Koch, S. (id.), Psychology: A Study of a Science, Vol. 2, 158-195. New York: WoGraw-Hill, 1959. 
Guthrie, E. R. The Psychology of Learning. New York: Harper and Row, 1935.

Gutteridge, M. V. The Duration of Attention in Young Children. Australian Council of Educational Research, Melbourne University Educational Research Series, Number 41, Oxford Unjversity Press, 1935.

Harms, I. S. "Listener Comprehension of Speakers of Three Status Groups," Language Speech, 4:109-112, 1961.

Herring, A. and Koch, H. I. "A Study of Some Factors Influencing the Interest Span of Preschool Children," Journal of Genetic Psychology, 38:249-279, 1930.

Hook, J.N. Cited within Petrie, C. R. "What is Iistening," An Experimental Evaluation of Two Methods for Improving Listening Comorehension Abilities, Purdue University Doctorial Thesis, 1961.

HuIl, C. I. "A Functional Interpretation of the Conditioned Reflex," Psychological Review, 36:498-511, 1929.

Hull, C. I. Principles of Behavior. New York: AppletonCentury-Crofts, 1943.

Hull, C. I. "Simple Qualitative Discrimination Learning," Psychological Review, 57:303-313, 1950.

James, W. The Principles of Psychology. Vol. 1, New York: Henry Holt, 1890.

Johnson, Wendal. "Do You Know How to Listen?" ETC. A Review of General Semantics, Vol. 7, No. 1, 3-9, Autumn, 1949.

Jones, M. E. Cited within Petrie, C. R. "What is Listening," An Experimental Evaluation of Two Methods for Imoroving Listening Comprehension Abilities, Purdue University Doctorial Thesis, 1961.

Keller, P. W. "Major Findings in Listening in the Past Ten Years," Journal of Communication, 10:29-38, 1960.

Lewis, M. "Exploratory Studies in the Development of a Face Schema." Paper presented at the Symposium on "The Origins of Social Behavior," American Psychological Association Meeting, Chicago, 1965. 
Lewis, M., Goldberg, S. and Rausch, M. "Attention Distribution as a Function of Novelty and Familiarity," Psychonomic Science, $7(6): 227-228,1967$.

Maccaby, E. E. and Konrad, D. W. "The Effect of Preparatory Sets on Selective Listening: Developmental Trends," Monograph Society for Research in Child Development, 32, No. 4 (Serial No. 112), 1967.

Martin, G. I. and Powers, R. B. "Attention Span: An Operant Conditioning Analysis," Exceptional Children, $33(8): 565-570,1967$.

McGuire, W. J. "A Syllogistic Analysis of Cognitive Relationships." In II. J. Rosenberg, C. I. Hovland, W. J. PicGuire, R. P. Abelson and J.W. Brehm, Attitude Organization and Change: An Analysis of Consistency imong Attitude Comonents. Wew Haven: Yale University Press, 1960.

Moray, N. Iistening and Attention. Baltimore, Maryland: Penguin Books, 1969, p. 107.

Moyer, K. E. and von Haller, Gilmer B. "Attention Spans of Children for Expeximentally Designed Toys," Journal of Genetic Psychology, 87:187-201, 1955.

Nichols, R. G. Factors Accounting for Differences in Comprehension of Wateria.ls Presented Orally in the Classroom, 1948 State University of Iowa Doctoral Thesis. In Duker, S. Listening: Readings. New York and London: The Scarecrow Press, Inc., 1966, p. 326 .

Nichols, R. G. and Lewis, T. R. Listening and Speaking. Dubuque, Iowa: Wm. C. Brown Company, 1954.

Nichols, R. G. "Iistening Instruction in the Secondary School," Bulletin of the National Association of Secondary School Principles, 36:158-174, May 1952.

Nichols, R. G. and Stevens, I. A. Are You Listening? New York: McGraw-Hill Book Company, Inc., 1959.

Oberly, H. T. "The Range for Visual Attention, Cognition and Apprehension," American Journal of Psychology, $35: 332-352,1924$.

Peterson, I. R. "Concurrent Verbal Activity," Psychological Review, 76(4):378-386, 1969. 
Petrie, C. R. "What is Listening," An Experimental Evaluation of Two Methods for Improving Listening Comprehension spilities, Purdue University Doctorial Thesis, 1961. Cited in luker, $S$. (ed.) Listening: Readings. New York and London: The Scarecrow Press, Inc., $1966, p .325$.

Rankin, P. T. "Frequency of Use of Listening," The Measurement of the Ability to Understand Spoken Language, University of liichigan Doctoral Thesis, 1926, pp. 77-96.

Rice, F. E. and Ratner, S. C. "Toward a Description of Language Behavior: II. The Iistenirg Action," Psychological Record, 17:493-502, 1967.

Rosenberg, S. and Curtiss, J. "The Effect of Stuttering on the Behavior of the Iistener," Journal of Abnormal Social and. Psychological Behavior, 49:355-361, 1954 .

Schacter, H. S. "A Method for Measuring the Sustained Attention of Preschool Children," Journal of Genetic Psychology, 43:339-371, 1933.

Skinner, B. F. Science and Human Behavior. New York: Macmillian, 1953.

Spence, K. W. Behavior Theory and Conditioning: New Haven: Yale University Press, 1956.

Spencer, E. An Investigation of the Maturation of Various Factors of Auditory Perception in Preschool Children. Evanston, Unpublished Doctoral Dissertation, Northwestern University, 1958.

Stevens, S. S. (ed.). Handbook of Experimental Psychology. New York and London: John Wiley and Sons, Inc., 1962, p. 902 .

Still, D. S. Cited in Petrie, C. R. "What is Listening," An Experimental Evaluation of Two Methods for Improving Listening Comprehension Abilities, Purdue University Doctorial Ihesis, 1961.

Taylor, S. E. "Listening: What Research Says to the Teacher," Research Pamphlet Series, Department of Classroom Teachers American Educational Research Association of the National Education Association, April, 1964, p. 19.

Tolman, E. C. "Prediction of Vicarious Trial and Error by Nieans of the Schematic Sowbug," Psychological Review, $46: 318-336,1939$. 


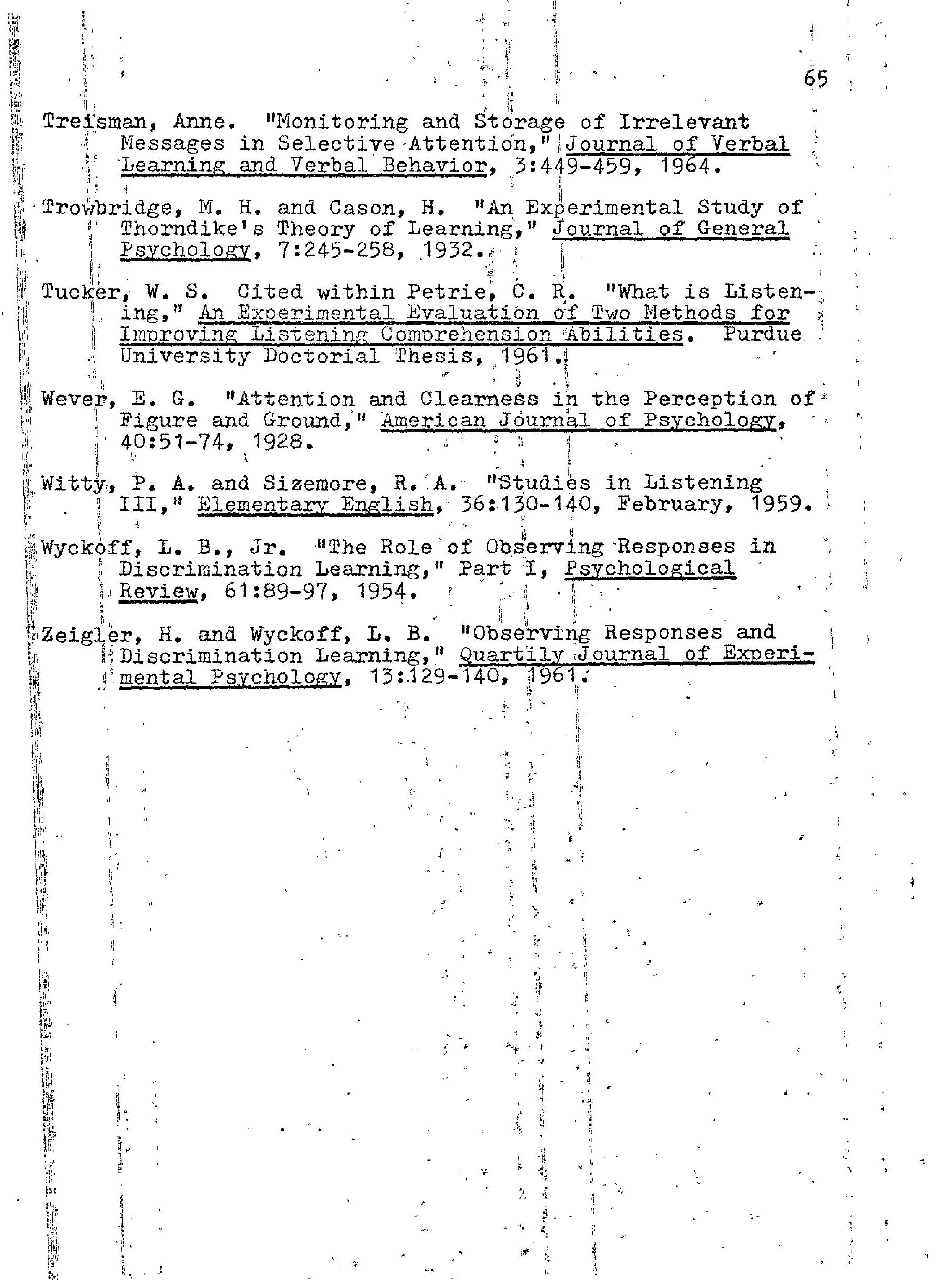




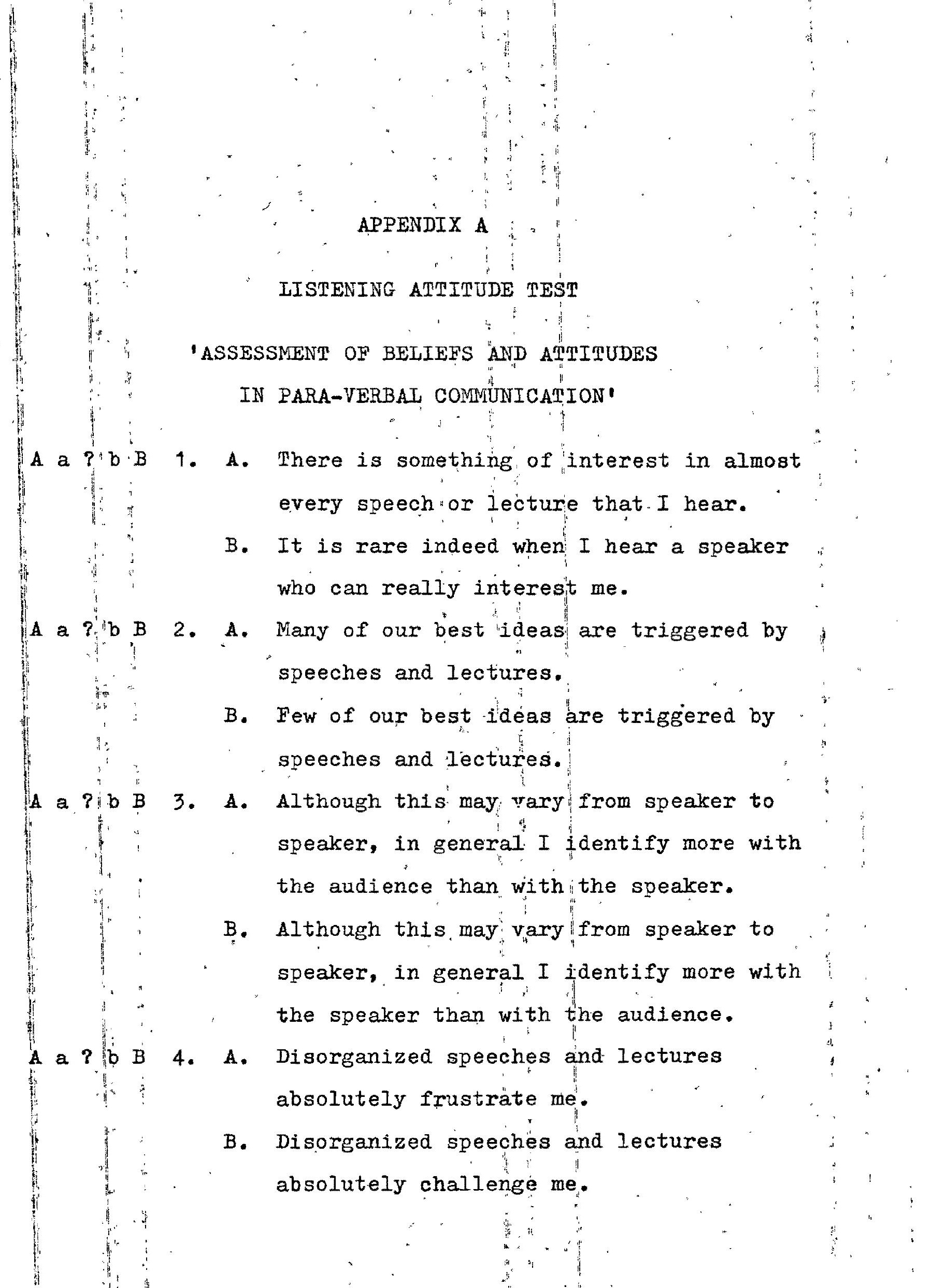


A al? b B 5. A. People who talk on eñgage in distracting behavior during a spëech should either shut up or leave the room.

B. If a speaker can not keep the attention of his listeners, it his ow fault.

A a ? b B 6. A. If a speaker does not communicate his ideas clearly, it is usually a waste of effort to continue listening closely. B. Speakers that are difficult to understand at first, are often the source of the most valuable ideas.

A a ? b B 7. A. No matter how long a person talks, I listen until he is through.

B. When someone is "töo long-winded, I tune them out:

A a ? b.B 8. A. When I miss the first part of a speech or lecture, I usually am impatient to find out what the speaker said before $I$ arrived.

B. When I miss the first part of a speech or lecture, I am usualily bored to tears throughout the part that I do hear.

A a ? B B 9. A. The voice, appearance and mannerisms of a speaker are often more interesting than what is being said: 
B. People who get all caught up in the voice, appearance "and mannerisms of a speaker miss the ideas and thrusts of the speaker's remarks.

A a ? b B 10. A. I get the most out of a speech or th lecture when" I relate it to things that the speaker does not discuss.

B. I get nothing out "of a lecture when a speaker fails to relate it to familiar ideas.

A a ? b B 11. A. I find it utterly impossible to understand a speaker who makes frequent use of emotional words' and phrases.

B. Frequent use of emotional words and phrases by a speaker often enhances my understanding of the speaker's ideas.

A $a ?$ ? B 12. A. I know from his first few comments whether or not I care to hear any more from a speaker.

B. I have difficulty ássessing the value of a speech or lecture" until it is over. 


\section{APPENDIX B}

PART A AND E FORM Am OF BROWN-CARISEN

IISTENING COMPREHENSION TEST

11. In the series of numbers $5-8-4-1-6$, the second number is

2. In the series of numbers $2-1 \div 4-5-8$, a series containing five numbers, the fourth"number is $?$

3. In the series of numbers $7-8-5-9-7$, the fourth number is ?

4. In the series of numbers $6-9-4=4-8-2$, the fifth number is ?

?

5. "In the series of numbers $8-1-9-5-3$, the third number is

6. In the series of numbers $1-9-5-7-3-5$, a series containing only odd numbers, the next to the last number is

7. In the list of words by - of - at - on, the word beginning with a is $?$

8. In the list of words at - by - to - of - in, a list containing five words, the second word is 
9. In the list of words of - to - at - on - by, the third word is

10. In the list of words by - at - of - to - in, the fourth word is

11. In the list of words on - an - in - of - at - to, the fifth word is

12. In the statement, isend three box tops with your name and address and 20 cents to Box 24, Denver 18, Colorado, to receive the special gift offer,' the number of cents to be encllosed is

13. In the statement just read, the box number was

14. Iisten to this explanation: Hefter inserting two small set. screws "in holes marked $A$ in the angle brackets marked $D$ on "the enclosed diagram, make three complete turns of each screw; then place the brackets on the wall in the desired position and fasten them into place with the, screws marked $\mathrm{C}$ on the diagram The number of turns of each set screw you were directed to make was

15. The number of set screws mentioned was

i6. Listen to these directions: 'Eight of you should walk 4 blocks up this street, turn to your left and continue 2 blocks to oak street, then angle off on Oak for one more block to the cormer house 
at 203 0ak.' The number of persons directed to make the trip was

17. The total number of blocks to the corner house on Oak Street is

That is the end of Part A.

Part E

A good vocabulary is important for several reasons. First, words win arguments--they persuade, they convince. i Once Iincoln, having failed to make a stubborn opponent see the error of his reasoning, said, "Well, let's see. How many "legs has a cow?"

"Four, of course," came the ready answer.

"That's right," said Lincoln. "Now suppose we call the cow's tail a leg, how many legs would the cow have?"

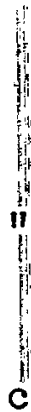

"Why, five, of course."

"Now that's where you're wrong," said Lincoln.

"Simply calling a cow's tail a leg dóesn't make it a leg.".

Second, you need a good vocabulary to make clear, concise explanations. Sometimes one word, provided it is the right one, explains everything. "For example, once when Paderewsi played before Queen Victoria, the sovereign exclaimed" with enthusiasm, "Mr. Paderewski, you are a wenius! was a

"Ah; your Majesty," he replied, "perhaps; but before genius I was a drudge." 
Words are important for a third reason--to illuminate experience. Max Eastman, writing about how to enjoy poetry, says that most Americans, confronted with a poem, mistake it for a conundrum. They think their part is to dodge the simple impact of the words, and sneak behind them in search of a moral, or a piece of extra-subtle information.

Poetry is using words, not to record or convey information, but to cherish or illuminate experience. If the poet can communicate to you the refined, essential quality of any genuine moment of his life, or any imagined life, that is enough. Don't ask for more. If you get something more, it is so much velvet. But if you are anxiously on the watch for it, you will miss the whole thing.

Eastman then goes on to mention a poem of his called "Egrets," which attempts to give something more. He says: "I once had a friend in Texas who loved to paddle around marshy islands taking wonderful pictures of these slender, broad-winged, snow-white birds. One day while we were looking at his pictures, my friend's tall, slim daughter, the most beautiful thing I saw in Texas, sat silently on the arm of her father's chair, attentive yet remote. In my feelings, her beauty merged in some subtle way with that of the birds and furnished the inspiration for my poem, 'Egrets,' which describes her as being 'kin to their slim hauteur,' as being 'gentle and yet far away as wings upon wild water." " 
Finally, words make the difference between boring or interesting someone. You may have fascinating things to tell, but you need the right words if you want to make them truly interesting. Notice how the right words make this an interesting story.

The country is India. At a dinner party the talk had turned to poise and self-control, and the old dispute: Which wâs more reliable in a crisis, man or woman? The males present, army officers and civil servants, agreed that women were the masterpieces of creation; their one defect was that they went into hysterics in a crisis. That was when you needed men.

All the ladies placidly concurred, except the hostess. At the height of the discussion she called a native boy. "Ali! Kindly fetch a bowl of milk at once and put it on the filoor."

With a terrified roll of his eyes the poy ran to obey, placing a jade bowl on the flagstone, close to the mistress of the house. Then he stood back, holding a looped whip in his hand, as, from under the white napery of the table, there slithered a long bloated thing, yellowish-brown with black and white marks. The cobra approached the milk and the native boy fell on it and killed it."

"Well;" puffed a red-faced colonel," "how on earth did you know that snake was under the table?"

"It was coiled," replied the hostess, "around my ankle." 
Now let's see how we may increase our vocabulary. In other words, since vocabulary is so all-important, how can we build one that will convince, explain, or interest others more effectively?

In the first place, what about the G.I. way of building a foreign-language vocabulary? Wouldn't that work equally well with strange English words?

Take Fernandex, a shy Mexican from one of the big sheep ranches of the Southwest. When the Army picked him up at 18 and started him on basic training, he was desperately homesick. He couldn't write home. And when anyone sent him a letter, he couldn't read it. At Fort Riley they put him in the Special Training
Troop with other representatives of our nation's 4,000,000 iliterates. After 8 weeks he was able to sign the payroll and was crazy with happiness. At the end of 13. weeks he was following the news and writing letters home. Navy. Such "Go-devil" teaching is common in the Army and

Think of the 2 or 4 years usually spent in studying French or Spanish. In the Army they teach you the bread and butter essentials of a language in 8 to 12 hours. Suppose our schools take up the Army-Navy technique. You'll first find the class around a phonograph, learning as a child learns his own language--by listening to and imitating a native speaker. After 15 to 20 minutes' work 
with records, the teacher fires simple questions at the students. All questions, all answers, even from the first lesson, are in the foreign tongue.

1" This language technique emphasizes the importance of using the words added to your vocabulary.

Then, there is the dictionary-study way. The dictionary has had a fascinating history in this country, from the time Noah Webster first got interested in preparing one. At the end of his first year's work, Webster estimated that his dictionary would require the incessant labor of 5 years more. It required 18, and it was in $182^{\prime} 8$ that his American Dictionary of the English Ianguage was published. It contained 70,000 entries.

But $\$ 20$ was a high price, and many of the 5500 original sets were still unsold in 1840, when Noah brought out a revised edition at \$15: This went padly, too. "After Webster's death, the Merriams, small job printers, obtained his copyrights and began a new revision of the dictionary. It's publication in 1847--one volume, \$6--was an immediate success. Slightly more than a hundred years later, the big Webster's New International Dictionary, it Second Edition, appeared. Its editor-in-chief, Neilson, was assisted by 207 special editors, expert in such diverse ifields as astrophysics, locksmithing, and archery. Now how should this invaluable reference book be used as a vocabulary-building aid? Well, we can learn a few 
things from Uncle George, who was as fond of words as an entomologist is of ants. The first thing he did when he came to pass the winter with us was to have the big dictionary brought into the dining, room. Hardly a meal was finished without some of us children jumping up to consult that lictionary. We found we could have as much fun with it as with any game we played.

One morning Uncle George asked if we knew what exiguous meant. "Well, I sort of half know," I said. $\|_{1}$

"If you don't know exactly," Uncle George replied, "you can't use it properly. It's like recognizing a man by hi's clothes. You can identify him, but you don't know much "about his character."

After I'd consulted the big dictionary, Uncle George "said, "Now repeat the word aloud three times."

He insisted that we must use each new word in a sentence at least three times a day. Somehow the new words made us feel mentally richer. When we talked we had a feeling of confidence, the way you do when you have money!

Uncle George would also show us what interesting istories the dictionary contained. He had us look up the word nice and read the dictionary story of a word that insisted on being a compliment instead of an insult. "Give me three words derived from the names of cities;" he used to say in another of his dictionary word- 
games: "And so it went. That's how Uncle George showed us the fun of using the dictionary.

Suppose we use a concise statement by Funk to summarize this approach. He says, when you read or hear an unfamiliar word, make a note of it and look it up later in the dictionary. If you think it, will be useful to you, write it down with its pronunciation and its simple definition. Then say the new word out loud several times and use it as soon as possible in your conversation or in a letter. Be sure to review your list from time to time, for new words slip easily from the mind.

"Then there is the synonym-study"way. A study of synonyms is one of the surest ways of enriching your vocabulary. But very few words are exactly alike. For instance, hate, loathe, despise, abhor, detest, and abominate are synonyms, but each shows a slightly different facet of one central idea. Watch the "car "cards, the billboards, and advertisements in magazines and newspapers. Pick out the striking words and see how many synonyms you can think of for each of them.

And don't overlook the derivation or word-history approach. Searching out the history of a word often helps clarify and fix its meaning.: When we find, for instance, that crestfallen refers to the drooping coxcomb of a rooster that has been beaten in a fight, and that sediment rilly signifies something that "sits" on the bottom, 
these words become more vivid. Word histories are both fascinating and helpful.

The word-a-day plan, the lastiof the five methods to be recommended, stresses regularity and orderliness. You may loaf along at a one-a-day rate or step along at a five-a-day speed, depending on how ambitious you feel. It * has been proved again and again that if you will regularly add new words to your vocabulary, and use them accurately and aptly in your conversation, you will. increase your self-confidence, and gain wider social acceptance and greäter influence in your community.

So much for the separate methods. Whichever method or combination of methods you decide to huse, remember that the important thing is to tailor it to your own needs. A method, that suits some people may not suit you, although you, can probably modify it to do so.

\section{Questions}

"56. What animal was mentioned in the Iincoln story?

57. Before whom did Paderewski play?

58. Who wrote the poem, 'Egrets'?

59. Where did the poet's picture-taking friend live?

60. What was poetry said to be an attempt to do?

61." What are women said to do in "a crisis?

62. In the Army program the basic essentials of a language were taught in 8 to 12 . . what? 
63. Fernandex was spoken of as one of how many of our nation's illiterates?

64. "For how much did Webster's original dictionary sell?

65. Who was the editor-in-chief of Webster!'s New International Dictionary, Second Edition?

66. What word did Uncle George havie the children look up?

67. To illustrate the helpfulness of word histories, mention was made of the derivation of "what word?

68. How many major vocabulary-building methods were mentioned specifically?

69. What was the central idea of the lecture?

70. Which of the parts of the lecture was least directly related to the central idea?

71. The Iincoln story was used in this lecture to show the importance of a good vocabulary in . . what?

72. Which specific vocabulary-building method was not given a separate place in the organization of the Iecture?

73. From the Paderewski story what would one infer that he thought?

74. That part of the lecture about Army-Navy language teaching suggests that vocabulary building is largely a matter of . . what?

75. Paderewski would probably consider desirable vocabulary growth as . . what? 
76. The discussion of word histories implies that we remember best those things which are most... what?"

That is the end of the test. 


\section{APPENDIX C}

INPER-ITEM CORRELATION MATRIX

OF THE TOTAL POPULATION

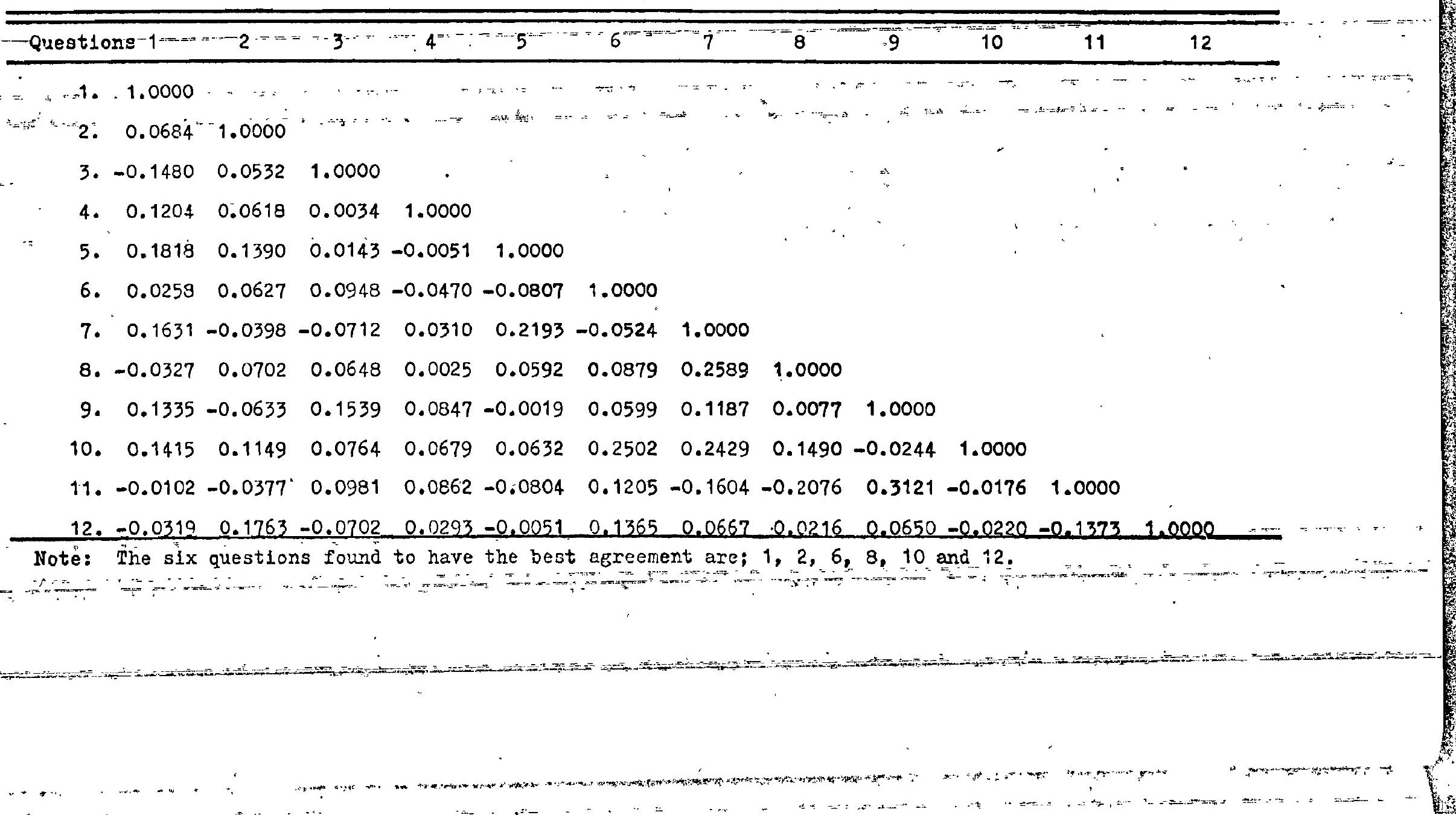


APPENDIX D

VAIIDITY, DIFFICULTY AND SPIIT HALF RELIABILITY COEFFICIENTS FOR THE BROWN-CARLSEN IISTEN-

ING COMPREHENSION TESTS, FORM Am

Validity and Difficulty Data

\begin{tabular}{cccccc}
\hline & \multicolumn{2}{c}{$\begin{array}{c}\text { Number } \\
\text { of Items }\end{array}$} & Validity & \multicolumn{2}{c}{ Difficulty } \\
Range & & Mean & Range & Mean \\
& 17 & $22-70$ & 37.8 & $30-84$ & 65.9 \\
A & 20 & $35-75$ & 48.0 & $38-85$ & 62.9 \\
B & 8 & $32-63$ & 44.1 & $30-84$ & 64.1 \\
D & $9 *$ & $30-72$ & 50.4 & $31-84$ & 61.0 \\
D & 21 & $26-59$ & 37.2 & $27-92$ & 58.4 \\
\hline & 75 & $22-75$ & 42.5 & $27-92$ & 62.2 \\
\hline
\end{tabular}

* One item revised subsequent to tryout

Reliability Data Obtained from

Three Separate Communities

\begin{tabular}{|c|c|c|c|c|}
\hline \multirow[b]{2}{*}{ Community } & \multicolumn{2}{|c|}{ Grade 10} & \multicolumn{2}{|c|}{ Grade 12} \\
\hline & $\mathrm{N}$ & $r_{1 I^{*}}$ & & $r_{1 I *}$ \\
\hline $\begin{array}{l}\text { Huron, So. Dakota } \\
\text { Jacksonville, Illinois } \\
\text { Gardiner, Maine }\end{array}$ & $\begin{array}{l}147 \\
200 \\
146\end{array}$ & $\begin{array}{l}.86 \\
.86 \\
.85\end{array}$ & $\begin{array}{r}120 \\
124 \\
97\end{array}$ & $\begin{array}{l}.84 \\
.85 \\
.90\end{array}$ \\
\hline
\end{tabular}

the Spearman-Brown formula. 


\section{APPENDIX E}

INSTRUCTIONS READ TO SUBJECTS BEFORE BROWNCARISEN IISTENING COMPREHENSION TEST

Fill in your name and the other information called for on the left hand side of the answer sheet. Be sure to fill in all the information accurately. The date of the testing is May 14th, 1971. Be sure to record the year, month ard day of your birth.

Much of what we learn is obtained by listening. It is as important to know how well you understand what you hear as it is to know how well you understand what you read. "Part A is called Immediate Recall." All work must be pone mentally and answers recorded on la separate answer sheet! "Listen carefully while I read the sample question. In a series of numbers $4-5-3-2-1$, the first number is _ ? Yes, the first number is 4. Therefore, In the sample on your answer sheet, the answer space under the 4 has been filled in. If the correct "choice is none of those given, you should fill in the answer space under $N$. 11 The others are to be done in the same manner. Listen carefully and try to remember what I say I shall read each question sonly once.

The above directions were read according to the test The above directions were read according to the test 
manual of the Brown-Carlsen Listening Comprehension Test Form Am (Brown and Carlsen, 1953).

Part $E$ is called Iecture Comprehension. In this part I shall read you a fairly lengthy selection entitled "Increasing Your Vocabulary." Iisten carefully as I read because, after I have finished, you will be required to answer questions about the selection. Do not take notes on what I read. Just listen carefully."

After reading "Increasing Your Vocábulary," further directions follow.

"That is the end of the lecture." Now turn over your answer sheet. Look at the sample. The question is, What is the title of the Lecture?' Decide, which of the five choices given is correct. Choice 'c' Increasing Your Vocabulary, is the correct title. Therefore, the answer ispacelunder ' $c$ ' has been filled in on the answer sheet. "Are there any questions? Iisten carefully; I shall read "ach question only once."

I : The above directions were read according to the test manual, Form Am of the Brown-Carlsen Listening Comprehension Test (Brow and Carlsen, 1953). 
INSTRUCTIONS READ TO SUBJECTS BEFORE

IISTENING ATTITUDE TEST

This is a choice of opinion study relating to the assessment of beliefs and attitudes in para-verbal communication. The study is concerned with one aspect of the communication process in our society.

This questionnaire is in no way related to your class and your identity will be anonymous.

Please answer the questions on the basis of your general experience and opinion of communication situations. Indicate by circling the item that most accurately represents your opinion. Indicate your opinion by using the lettered responses, resorting to the question (?) response only when you find it absolutely impossible to use the other responses. Read the questions and answer them quickly without pondering.

A more detailed description of the purpose and results of this study will be given to your instructor.

$A=$ strongly prefer statement "A" over statement "B"

$a$ = somewhat prefer statement "A" over statement "B" ? = both statements are equally acceptable to me $l_{b}=$ somewhat prefer statement "B" over statement "A" $B$ = strongly prefer statement "B" over statement "A" 


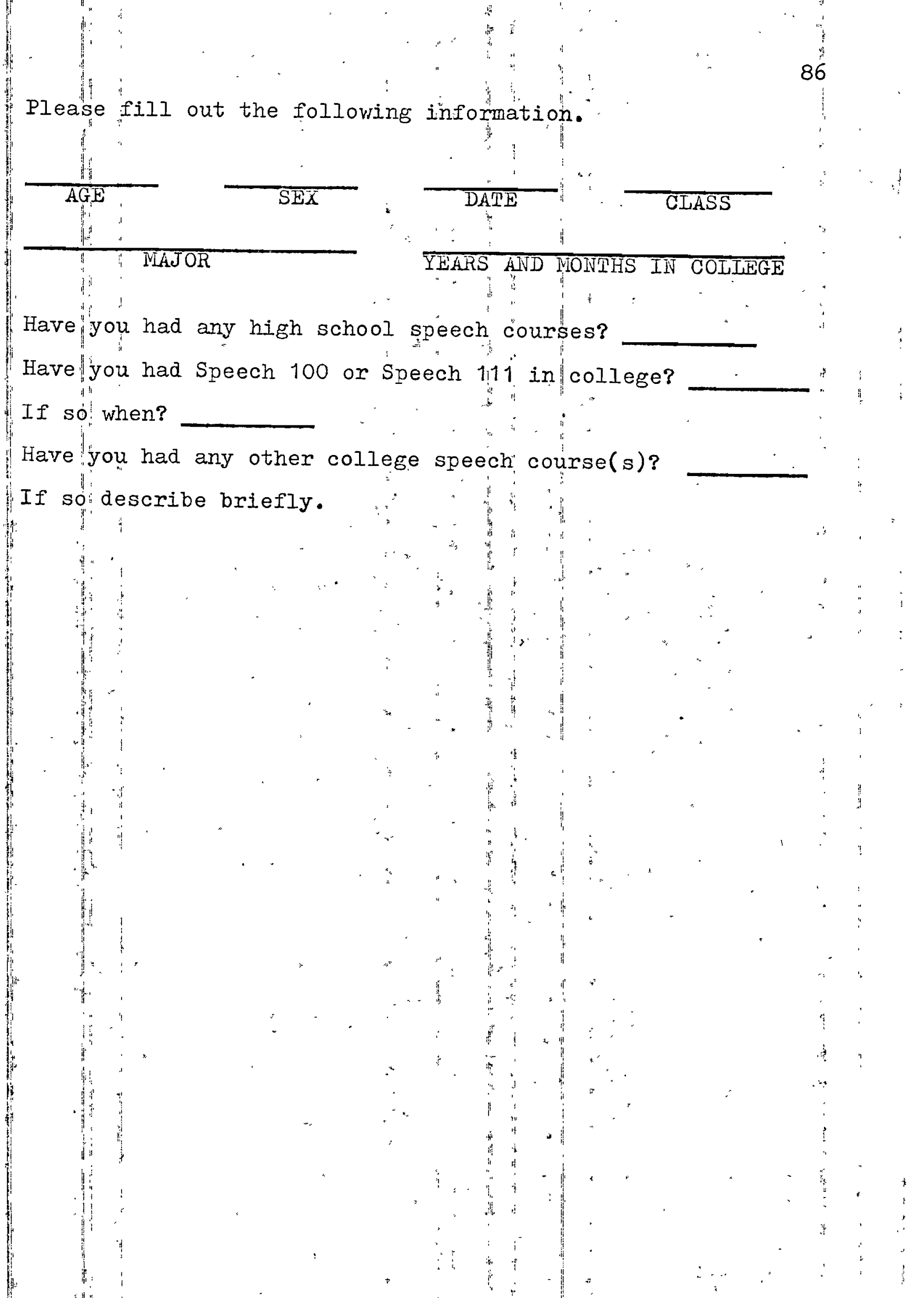




\section{APPENDIX $G$}

RAW DATA ON THE IAT AND THE BROWN-CARLSEN TEST FORM Am PARTS A, E AIVD A AND E COMBINED

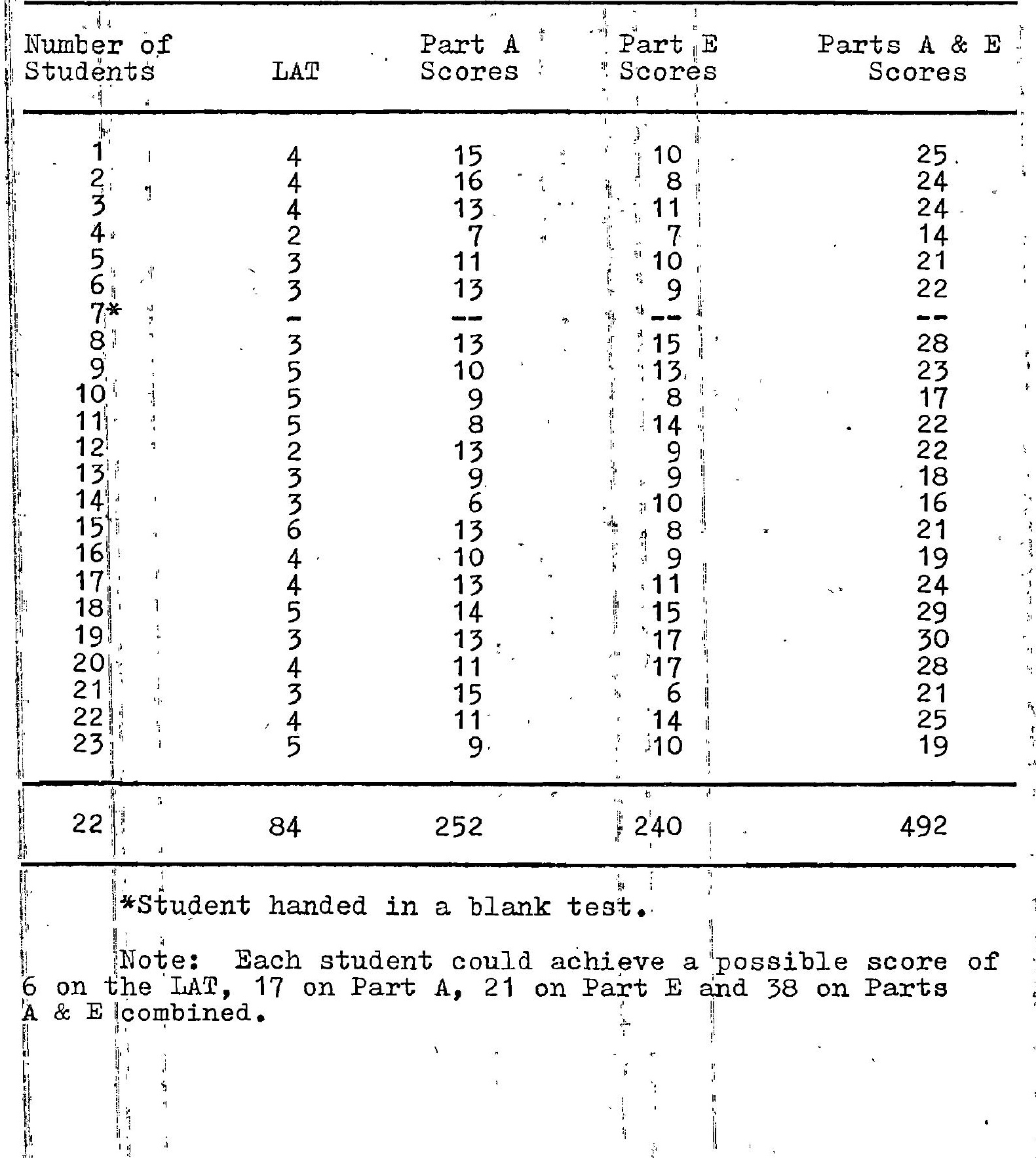

